\title{
PORTFOLIO CHOICE IN RETIREMENT: HEALTH RISK AND THE DEMAND FOR ANNUITIES, HOUSING AND RISKY ASSETS
}

\author{
Motohiro Yogo* \\ CRR WP 2009-3 \\ Released: January 2009 \\ Draft Submitted: January 2009
Center for Retirement Research at Boston College
Hovey House
140 Commonwealth Avenue
Chestnut Hill, MA 02467

Tel: 617-552-1762 Fax: 617-552-0191

\begin{abstract}
* Motohiro Yogo is an assistant professor of finance at the Wharton School at the University of Pennsylvania. The research reported herein was pursuant to a Sandell grant from the U.S. Social Security Administration (SSA) funded as part of the Retirement Research Consortium (RRC). The findings and conclusions expressed are solely those of the authors and do not represent the views of SSA, any agency of the Federal Government, the RRC, the University of Pennsylvania, the National Bureau of Economic Research, or Boston College. For comments and discussions, I thank Andrew Abel, Franklin Allen, Jeffrey Brown, David Chapman, Raquel Fonseca, Eric French, John Jones, Ahmed Khwaja, and Olivia Mitchell. I also thank seminar participants at the Federal Reserve Bank of New York, Nomura Securities, Northwestern University, Princeton University, University of Illinois at Urbana-Champaign, University of Pennsylvania, University of Tokyo, the 2008 Michigan Retirement Research Center Research Workshop, and the 2008 Texas Finance Festival. This paper is based upon work supported by the University of Pennsylvania through grants from the National Institutes of Health-National Institute on Aging (grant number P30-AG12836), the Boettner Center for Pensions and Retirement Security, the National Institutes of Health-National Institute of Child Health and Human Development Population Research Infrastructure Program (grant number R24-HD044964), and the Rodney L. White Center for Financial Research.

(C) 2009, by Motohiro Yogo. All rights reserved. Short sections of text, not to exceed two paragraphs, may be quoted without explicit permission provided that full credit, including (C) notice, is given to the source.
\end{abstract}




\title{
About the Center for Retirement Research
}

The Center for Retirement Research at Boston College, part of a consortium that includes parallel centers at the University of Michigan and the National Bureau of Economic Research, was established in 1998 through a grant from the Social Security Administration. The Center's mission is to produce first-class research and forge a strong link between the academic community and decision makers in the public and private sectors around an issue of critical importance to the nation's future. To achieve this mission, the Center sponsors a wide variety of research projects, transmits new findings to a broad audience, trains new scholars, and broadens access to valuable data sources.

\author{
Center for Retirement Research at Boston College \\ Hovey House \\ 140 Commonwealth Avenue \\ Chestnut Hill, MA 02467 \\ phone: 617-552-1762 fax: 617-552-0191 \\ e-mail: crr@bc.edu \\ www.bc.edu/crr
}

Affiliated Institutions:

The Brookings Institution

Massachusetts Institute of Technology

Syracuse University

Urban Institute 


\begin{abstract}
This paper develops a consumption and portfolio-choice model of a retiree who allocates wealth among four assets: a riskless bond, a risky asset, a real annuity, and housing. Unlike previous studies that treat health expenditures as exogenous negative income shocks, this paper builds on the Grossman model to endogenize health expenditures as investments in health. I calibrate the model to explain the joint evolution of health status and the composition of wealth for retirees, aged 65 to 96, in the Health and Retirement Study. I use the calibrated model to assess the welfare gains of an actuarially fair annuity market. The welfare gain is less than $1 \%$ of wealth for the median-health retiree at age 65 , and the welfare gain is about $10 \%$ of wealth for the healthiest.
\end{abstract}




\section{Introduction}

As Baby Boomers approach retirement, the merit of retirement financial products, in particular annuities, has been a hot topic of debate in industry and public policy. Yet, little is understood about the asset allocation of retirees. In a world with uncertainty only over the time of death, a retiree without a bequest motive should fully annuitize wealth (Yaari 1965). Davidoff, Brown, and Diamond (2005) generalize the result by showing that full annuitization is optimal as long as markets are complete. In reality, retirees own more complicated portfolios allocated across four major asset classes: bonds (including cash), risky assets (including private businesses and stocks), annuities (mostly in the form of defined benefit pension plans and Social Security), and housing.

The primary risk that retirees face is health, which is inherently uninsurable and therefore makes markets incomplete. On the one hand, adverse health shocks require health expenditures to partially restore health. On the other hand, good health leads to longevity risk, that is, the risk of outliving one's financial wealth. In addition to health risk, a bequest motive may play a role in portfolio choice. Although there is a large literature on how labor-income risk affects the portfolio choice of working households, there has been relatively little work on how health risk affects the portfolio choice of retirees.

This paper develops a consumption and portfolio-choice model to explain the joint evolution of health status and the composition of wealth in retirement. Following the seminal work of Grossman (1972), I model health as a durable consumption good and health expenditures as investments in health. Health insurance is taken into account through the price of health expenditure in relation to consumption. Essentially, I extend the Grossman model to allow for portfolio choice between a riskless bond, a risky asset, a real annuity, and housing. Using data on general health status and asset holdings in the Health and Retirement Study (HRS), I calibrate the model to a population of retired unmarried females, aged 65 to 96 . The model explains the cross-sectional distribution of health status together with asset allocation as a function of age and health status. 
Previous work has shown that uncertainty over health expenditures can crowd out the demand for annuities and explain precautionary saving in liquid assets 11 However, this finding is based on a model in which health expenditures are essentially exogenous negative income shocks. When health expenditures are endogenized as investments in health, the precautionary motive to save in liquid assets essentially disappears. This is because the retiree can invest directly in health by accumulating health capital, rather than indirectly by accumulating liquid assets. As a consequence, the bequest motive becomes a relatively important ingredient in explaining the significant holdings of liquid assets that is observed in the data.

Are retirees currently under-annuitized? What would be the demand for annuities in a world with an actuarially fair annuity market? These questions cannot be answered by a model in which health expenditures are exogenous because an alternative market structure can change the endogenous accumulation of health. I use the calibrated Grossman model to assess the welfare gains of an actuarially fair annuity market. I find that the welfare gain is less than $1 \%$ of wealth for the median-health retiree at age 65 , and the welfare gain is about $10 \%$ of wealth for the healthiest. Because the welfare gain is small except for the healthiest retirees, the lack of demand for private annuities is less of a puzzle.

The remainder of the paper proceeds as follows. Section 2 develops a model of consumption and portfolio choice in retirement. Section 3 describes the relevant measures of health expenditures, health status, and asset holdings in the HRS. Section 4 presents the calibration and solution of the model. Section 5 presents a welfare analysis of an actuarially fair annuity market. Section 6 concludes.

\footnotetext{
${ }^{1}$ See Hubbard, Skinner, and Zeldes (1994), Palumbo (1999), De Nardi, French, and Jones (2006), and Ameriks, Caplin, Laufer, and Van Nieuwerburgh (2007) for an analysis of precautionary saving in bonds due to uncertain health expenditures. The analysis has been extended to include portfolio choice between bonds, risky assets, and annuities (Edwards 2005, Love and Perozek 2007, Pang and Warshawsky 2007, Turra and Mitchell 2004).
} 


\section{A Model of Consumption and Portfolio Choice in Retirement}

This section describes a model of consumption and portfolio choice in retirement. The key innovation, relative to previous models, is that health expenditure is a decision variable for the retiree. Consequently, the model allows for the endogenous accumulation of health. Picone, Uribe, and Wilson (1998) develop a related model in which the retiree can only save in a riskless bond, that is, a model without portfolio choice.

\subsection{Housing}

Although housing is the most important tangible asset for retirees, it has been ignored in previous analysis of portfolio choice in retirement. Cocco (2005), Hu (2005), and Yao and Zhang (2005) develop life-cycle models that incorporate housing in portfolio choice, but they focus on labor-income risk and abstract from health risk that is the main concern for retirees.

Let $D_{t}$ denote the housing stock at the beginning of period $t$. The stock $D_{t}$ incorporates both the size and the quality of the house. In each period $t$, the house depreciates at a constant rate $\delta \in(0,1]$. The retiree makes a net investment $E_{t}$ in the house, which can be negative in the case of disinvestment. The accumulation equation for housing is

$$
D_{t}=(1-\delta) D_{t-1}+E_{t},
$$

given an initial stock $D_{0}$.

\section{$2.2 \quad$ Health}

Following Grossman (1972), the retiree's health is modeled as a durable consumption good. Let $H_{t}$ denote the health stock at the beginning of period $t$. In each period $t$, health depreciates at a stochastic rate $\omega_{t} \leq 1$. The retiree dies if $\omega_{t}=1$, that is, if her health 
depreciates entirely. The retiree's maximum possible lifetime is $T$ so that $\omega_{T+1}=1$ with certainty.

After the health shock is realized in period $t$, the retiree makes an investment $I_{t}$ in health if she is still alive 2 Let $1\left\{\omega_{t}<1\right\}$ be an indicator function that takes the value one if the retiree survives period $t$, and let $1\left\{\omega_{t}=1\right\}=1-1\left\{\omega_{t}<1\right\}$. The accumulation equation for health is

$$
H_{t}=\left(1-\omega_{t}\right) H_{t-1}+1\left\{\omega_{t}<1\right\} I_{t},
$$

given an initial stock $H_{0}$.

\subsection{Consumption and Portfolio-Choice Problem}

\subsubsection{Budget Constraint}

The retiree enters each period $t$ with financial wealth $W_{t}$. The retiree uses wealth for consumption $C_{t}$, housing investment $E_{t}$ at the relative price $P_{t}$, and health investment $I_{t}$ at the relative price $Q_{t}$. The retiree saves the wealth remaining after consumption in $N$ financial assets. For each asset $i$, let $A_{i t}$ denote the retiree's savings at the end of period $t$. Let $R_{i, t+1}$ denote its gross rate of return from period $t$ to $t+1$. The intraperiod budget constraint is

$$
\sum_{i=1}^{N} A_{i t}=W_{t}-C_{t}-P_{t} E_{t}-Q_{t} I_{t} .
$$

The intertemporal budget constraint is

$$
W_{t+1}=\sum_{i=1}^{N} A_{i t} R_{i, t+1},
$$

\footnotetext{
${ }^{2} \mathrm{~A}$ natural constraint to impose on health is a disinvestment constraint, $I_{t} \geq 0$. However, this constraint does not bind in practice because health depreciates at a sufficiently high rate for individuals in retirement age. I therefore ignore the constraint, avoiding previous health stock as an additional state variable of the problem.
} 
given initial wealth $W_{1}$.

\subsubsection{Intraperiod Utility}

In each period that the retiree is alive, her utility flow is given by

$$
U(C, D, H)=\left[(1-\alpha)\left(C^{1-\phi} D^{\phi}\right)^{1-1 / \rho}+\alpha H^{1-1 / \rho}\right]^{1 /(1-1 / \rho)},
$$

where $\phi \in(0,1)$ and $\alpha \in(0,1)$. The parameter $\rho \in(0,1]$ is the elasticity of substitution between consumption and health. The restriction $\rho \leq 1$ assures that the marginal utility

of health becomes unbounded as the health stock approaches zero, so that the retiree never desires intentional death.

\subsubsection{Utility Maximization Problem}

If the retiree survives period $t$, she experiences a utility flow $U\left(C_{t}, D_{t}, H_{t}\right)$. If she dies in period $t$, she leaves behind tangible wealth,

$$
\bar{W}_{t}=W_{t}+(1-\delta) P_{t} D_{t-1},
$$

which is the sum of financial and housing wealth. The retiree has a joy-of-giving bequest utility over tangible wealth. Abel and Warshawsky (1988) show that a joy-of-giving bequest motive can be interpreted as a reduced form for an altruistic bequest motive.

The retiree maximizes the objective function

$$
\mathbf{E}_{1}\left[\sum_{t=1}^{T+1} \beta^{t-1} \prod_{s=2}^{t-1} 1\left\{\omega_{s}<1\right\}\left(1\left\{\omega_{t}<1\right\} \frac{U\left(C_{t}, D_{t}, H_{t}\right)^{1-\gamma}}{1-\gamma}+1\left\{\omega_{t}=1\right\} \frac{\left(\bar{u} \bar{W}_{t}\right)^{1-\gamma}}{1-\gamma}\right)\right]
$$

The parameter $\beta \in(0,1)$ is the subjective discount factor, and $\gamma>1$ is the relative risk aversion. The parameter $\bar{u}>0$ controls the strength of the bequest motive, which disappears as $\bar{u} \rightarrow \infty$. 


\subsection{Transforming the Problem in Terms of Total Wealth}

As stated above, financial wealth, housing stock, and health stock are all state variables of the consumption and portfolio-choice problem. The problem can be simplified significantly by collapsing the three state variables into one state variable called total wealth. The retiree's total wealth at the beginning of period $t$ is

$$
\widetilde{W}_{t}=W_{t}+(1-\delta) P_{t} D_{t-1}+\left(1-\omega_{t}\right) Q_{t} H_{t-1}
$$

In words, total wealth is the sum of financial wealth, housing wealth, and health capital. In the period in which she dies, the retiree's total wealth is equal to tangible wealth, that is, $\widetilde{W}_{t}=\bar{W}_{t}$.

Define savings in housing and health in period $t$ as

$$
\begin{aligned}
& A_{D t}=P_{t} D_{t}, \\
& A_{H t}=Q_{t} H_{t} .
\end{aligned}
$$

Then the intraperiod budget constraint (3) can be rewritten as

$$
\sum_{i=1}^{N} A_{i t}+A_{D t}+A_{H t}=\widetilde{W_{t}}-C_{t}
$$

Define the gross rates of return on housing and health from period $t$ to $t+1$ as

$$
\begin{aligned}
R_{D, t+1} & =\frac{(1-\delta) P_{t+1}}{P_{t}} \\
R_{H, t+1} & =\frac{\left(1-\omega_{t+1}\right) Q_{t+1}}{Q_{t}}
\end{aligned}
$$


Then the intertemporal budget constraint (41) can be rewritten as

$$
\widetilde{W}_{t+1}=\sum_{i=1}^{N} A_{i t} R_{i, t+1}+A_{D t} R_{D, t+1}+A_{H t} R_{H, t+1}
$$

The utility flow (5) in period $t$ can be rewritten as

$$
U_{t}\left(C_{t}, A_{D t}, A_{H t}\right)=C_{t}\left[(1-\alpha)\left(\frac{A_{D t}}{P_{t} C_{t}}\right)^{\phi(1-1 / \rho)}+\alpha\left(\frac{A_{H t}}{Q_{t} C_{t}}\right)^{1-1 / \rho}\right]^{1 /(1-1 / \rho)} .
$$

Let $A_{t}=\left\{A_{1 t}, \ldots, A_{N t}, A_{D t}, A_{H t}\right\}$ be the set of savings in all assets, including housing and health. The Bellman equation is

$$
\begin{aligned}
J_{t}\left(\widetilde{W}_{t}\right)= & \max _{C_{t}, A_{t}} \frac{U_{t}\left(C_{t}, A_{D t}, A_{H t}\right)^{1-\gamma}}{1-\gamma} \\
& +\beta \mathbf{E}_{t}\left[1\left\{\omega_{t+1}<1\right\} J_{t+1}\left(\widetilde{W}_{t+1}\right)+1\left\{\omega_{t}=1\right\} \frac{\left(\widetilde{u} \widetilde{W}_{t+1}\right)^{1-\gamma}}{1-\gamma}\right]
\end{aligned}
$$

\subsection{Financial Assets}

To complete the model, I specify the retiree's trading universe and portfolio constraints. The trading universe consists of three financial assets, which capture the key economic features of actual assets held by retirees.

\subsubsection{Riskless Bond}

The first asset is a riskless bond, which has a constant gross rate of return $R_{1 t}=\bar{R}_{1}$. For the period 1971 to 2006, the average real return (in excess of the CPI inflation rate) on the one-year Treasury bond was $2.6 \%$. Based on this estimate, I set $\bar{R}_{2}=1.026$.

The retiree can short the bond up to a fraction $\lambda \in[0,1)$ of the value of the house. A short position on the bond can be interpreted as a mortgage or a home equity line of credit. 
Therefore, the portfolio constraint for savings in the bond is

$$
A_{1 t} \in\left[-\lambda P_{t} D_{t}, W_{t}-C_{t}-P_{t} E_{t}-Q_{t} I_{t}\right]
$$

I calibrate the borrowing limit to be $20 \%$ of the value of the house. This value is consistent with the evidence that retirees are less able to tap into their home equity than younger working households (Sinai and Souleles 2007).

\subsubsection{Risky Asset}

The second asset is a risky asset, which has a stochastic gross rate of return

$$
R_{2 t}=\bar{R}_{2} \nu_{2 t}
$$

where $\log \nu_{2 t} \sim \mathbf{N}\left(-\sigma_{2}^{2} / 2, \sigma_{2}^{2}\right)$ is independently and identically distributed (i.i.d.). For the period 1971 to 2006, the real return (in excess of the CPI inflation rate) on the Center for Research in Securities Prices value-weighted index had a mean of $7.9 \%$ and a standard deviation of $17.2 \%$. Based on these estimates, I set $\bar{R}_{2}=1.056$ and $\sigma_{2}=0.172$. In the life-cycle consumption and portfolio-choice literature, models are commonly calibrated with an equity premium that is lower than the historical average excess stock returns (e.g., Cocco, Gomes, and Maenhout (2005)). This practice is justified through stock-market participation costs, whether they are actual or psychological costs.

The retiree may not take a short or a leveraged position in the risky asset. Therefore, the portfolio constraint for savings in the risky asset is

$$
A_{2 t} \in\left[0, W_{t}-C_{t}-P_{t} E_{t}-Q_{t} I_{t}\right]
$$




\subsubsection{Real Annuity}

The third asset is a real annuity, which has a gross rate of return that is contingent on survival,

$$
R_{3 t}=\left\{\begin{array}{ll}
\bar{R}_{3} / p_{t} & \text { if } \omega_{t}<1 \\
0 & \text { if } \omega_{t}=1
\end{array} .\right.
$$

In this specification, $p_{t}$ is an actuarially fair survival probability in period $t$, which is a deterministic function of gender, birth cohort, and age. If a unit of the annuity is defined as a claim that pays off one unit of consumption in every period until death, its actuarially fair price in period $t$ is

$$
P_{3 t}=\sum_{s=1}^{T-t} \frac{\prod_{u=1}^{s} p_{t+u}}{\bar{R}_{3}^{s}} .
$$

I use equation (20) to calibrate the return on the annuity, using $\bar{R}_{3}=1.026$ to match the real return on the one-year Treasury bond. The survival probabilities are those for a female born in the 1940 cohort, which are reported by the Social Security Administration (Bell and Miller 2005, Table 7). Similarly, I use equation (21) to calibrate the price of the annuity, setting $T$ to age 96 .

Almost all individuals enter retirement with implicit holdings of annuities, either through a defined benefit pension plan or Social Security, and subsequently do not increase their holdings of annuities. I model this situation as follows. Let $B_{3 t}$ be the holdings of the annuity at the end of period $t$, so that savings in the annuity is $A_{3 t}=P_{3 t} B_{3 t}$. The individual enters retirement with an endowment $B_{0}$ of the annuity. For all periods $t \geq 1$, the portfolio constraint for the annuity is $B_{3 t}=B_{3, t-1}$. In Section 5, I relax this constraint and allow the retiree to purchase additional units through an actuarially fair annuity market, which corresponds to the constraint $B_{3 t} \geq B_{3, t-1}$. 


\subsection{Relative Price of Housing}

I model the gross rate of return on housing as

$$
R_{D t}=\bar{R}_{D} \nu_{D t},
$$

where $\log \nu_{D t} \sim \mathbf{N}\left(-\sigma_{D}^{2} / 2, \sigma_{D}^{2}\right)$ is i.i.d. The dynamics of the relative price of housing is then determined by equation (12), normalizing the initial price level at $P_{1}=1$.

Using equation (12) and the Bureau of Economic Analysis's depreciation rate of 1.14\% on residential capital, I compute the return on the Case-Shiller Composite-10 Home Price Index. For the period 1988 to 2006, the real housing return (in excess of the CPI inflation rate) had a mean of $2.2 \%$ and a standard deviation of $7.0 \%$. Based on these estimates, I set $\bar{R}_{D}=1.022$ and $\sigma_{D}=0.070$.

\section{$3 \quad$ Health and Retirement Study}

\subsection{Sample}

The HRS is a panel survey designed to study the health and wealth of the elderly in the United States. I use the RAND HRS data files, which is a version of the HRS cleaned and processed by the RAND Center for the Study of Aging. I use the first six waves of the HRS, which cover the period 1992 to 2002. I focus on those born 1901 to 1940, which includes the cohorts associated with Study of Assets and Health Dynamics Among the Oldest Old (born before 1924), the Children of Depression (born 1924 to 1930), and the initial HRS (born 1931 to 1941).

I focus my analysis on the sample of retired unmarried females, aged 65 to 96 . The focus on unmarried individuals is dictated by the fact that married individuals maximize a more complicated objective function that depends on the health and survival of the spouse. The focus on females is dictated by the fact that females live longer than males, and hence, have 
a longer (and arguably more interesting) retirement cycle. The focus on retirees younger than 96 is dictated by the fact that there are very few survivors in the data set beyond that age.

Because retirees are interviewed every two years, I code age in groups of two years from the 65-66 to the 95-96 age group. Hence, there are a total of 16 periods in the retirement cycle, indexed as $t=1, \ldots, 16$. All empirical analysis uses the person-level analysis weight to weight observations.

\subsection{Descriptive Statistics for Health Expenditure}

Retirees in the HRS are asked to report various measures of health every two years. The chosen measure of health for my study is the self-reported general health status, which is categorized as poor, fair, good, very good, or excellent. Insofar as health enters the retiree's utility function, self-reported health status is a relevant measure of health for mapping the model to the data. As reported in Wallace and Herzog (1995), self-reported health status is highly correlated with objective measures of physical and mental health. Moreover, it is a significant predictor of future mortality as reported below.

The RAND HRS data set contains a measure of total health expenditures on hospitals, nursing homes, doctor visits, dentist visits, outpatient surgery, prescription drugs, home health care, and special facilities. It also contains a measure of out-of-pocket health expenditures, that is, the part of total health expenditures paid for by the retiree. Almost all retirees (over 99\%) report health insurance coverage through Medicare, Medicaid, or insurance from a previous employer.

Panel A of Table1 1 reports the median of total health expenditures, in real 2000 dollars, by age and health status. Total health expenditures rise in age. The median health expenditure is $\$ 480$ per year for retirees aged 65 to 72 , and $\$ 646$ per year for retirees aged 89 to 96 . Total health expenditures also fall in health status. For retirees aged 65 to 72 , the median health expenditure is $\$ 920$ per year for those in poor health, and $\$ 400$ per year for those in excellent 
health.

Panel B reports the median of out-of-pocket health expenditures, in real 2000 dollars, by age and health status. Out-of-pocket health expenditures display the same pattern, namely, rising in age and falling in health status. In terms of magnitude, however, the decline in health status is less pronounced than that for total health expenditures. In other words, those in poor health pay a lower share out-of-pocket than those in excellent health.

To get a sense of the composition of health expenditures, Table 2 reports the percentage of retirees utilizing the indicated health care by age and health status. Panel A shows that almost all retirees visit doctors and dentists, regardless of age and health status. This fact is consistent with the view that everyone requires some minimal level of medical services for the maintenance of health and the prevention of illnesses. Panel B shows that the use of prescription drugs is rising in age and falling in health status. The same pattern holds for the use of hospitals and outpatient surgery in Panel $\mathrm{C}$, and the use of nursing homes, home health care, and special facilities in Panel D. These patterns are consistent with the view that the unhealthy require extra services for the treatment for their illnesses.

\subsection{Relative Price of Health Expenditure}

For each retiree, I compute the out-of-pocket health expenditure share as a ratio of out-ofpocket health expenditures to total health expenditures. I use a censored regression model to estimate the out-of-pocket health expenditure share as a function of cohort dummies, health status, age, and the interaction of health status with age.

Table 3 reports the estimated regression model. On the one hand, the relation between the out-of-pocket expenditure share and health status is mostly insignificant. On the other hand, the out-of-pocket health expenditure share rises significantly in health status. This relation suggests that insurance subsidizes medical services that treat the unhealthy more so than those that maintain the health of the already healthy.

I model health insurance through the price of health expenditure in relation to consump- 
tion. Let $\widehat{Q}_{t}\left(H_{t}^{*}\right) \in[0,1]$ denote the predicted health expenditure share for the 1931-1940 cohort as a function of age and health status. The relative price of health expenditure is

$$
Q_{t}=Q_{1} e^{q t} \widehat{Q}_{t}\left(H_{t}^{*}\right)
$$

where the initial price level is normalized as $Q_{1}=1$. For the period 1971 to 2006 , the average log growth rate of the CPI for medical care relative to that for all items less medical care was $1.9 \%$. Based on this estimate, I set $q=0.019$.

\subsection{Transition Probabilities for Health Status}

In order to implement the model, I need an empirical analog to the accumulation equation for health (2). I use data on self-reported general health status and an ordered probit model to estimate the transition dynamics of health. In each period $t$, the retiree reports her health status $H_{t}^{*}$. The health status depends on a latent variable, $H_{t}$, through

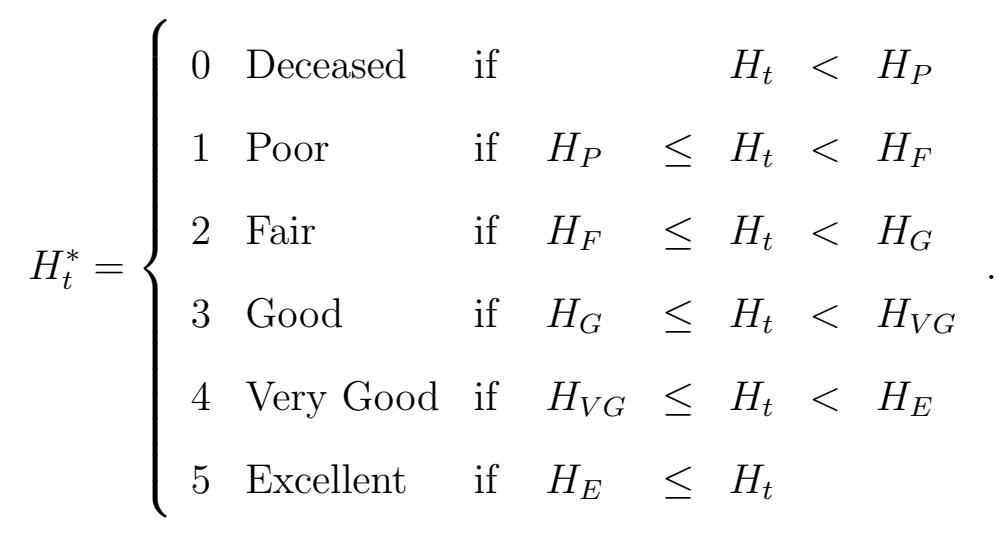

(See Wagstaff (1986) and Khwaja (2002) for a similar approach.) I model $\log H_{t}$ as a function of cohort dummies, health status at $t-1$, age, and the interaction of health status at $t-1$ with age. I also control for log total health expenditure at $t$, where expenditures below $\$ 500$ are truncated at $\$ 500$.

Table 4 reports the estimated probit model. As is expected, health status at $t$ is positively related to health status at $t-1$. In other words, retirees in poor health on average remain 
in poor health. The coefficient on age is negative, which implies that health status declines in age. The coefficient on total health expenditures is positive, which implies that health expenditures are indeed investments that improve health status.

Using the estimated probit model, I compute the transition probabilities for health status, $\operatorname{Pr}\left(H_{t}^{*} \mid H_{t-1}^{*}\right)$, in the absence of health expenditures. The predicted probabilities are those for the 1931-1940 cohort with health expenditures below $\$ 500$. Figure 1 plots the transition probabilities by age for each category of health status. Mortality is related to health status in a natural way. Conditional on being in poor health, death is the most likely outcome in the subsequent period. Conditional on being in excellent health, death is the least likely outcome in the subsequent period.

\subsection{Asset Allocation in Retirement}

Retirees in the HRS report holdings of four major asset classes. The first asset class is "bonds", which consists of checking, savings, and money market accounts; CD, government savings bonds, and T-bills; bonds and bond funds; and the safe part of IRA and Keogh accounts. From the value of bonds, I subtract the value of liabilities, which consists of all mortgages for primary and secondary residence; other home loans for primary residence; and other debt.

The second asset class is "risky assets", which consists of businesses; stocks, mutual funds, and investment trusts; and the risky part of IRA and Keogh accounts. Following Hurd (2002), I assume that half of the value of IRA and Keogh accounts is safe, and the other half is risky.

The third asset class is "annuities", which consists of employer pension or annuity; Social Security disability and supplemental security income; and Social Security retirement.

Following Gustman, Mitchell, Samwick, and Steinmeier (1997), I use data on pension and Social Security income to impute its asset value in each retiree's portfolio. The asset value of annuities is defined simply as the total pension and Social Security income times the price 
of a real annuity (21). This imputation abstracts from the fact that not all pension income is indexed to the CPI.

The fourth asset class is "housing", which consists of primary and secondary residence.

I use a censored regression model to estimate the portfolio share in each of the four assets as a function of cohort dummies, health status, age, and the interaction of health status with age. Table 5 reports the estimated regression models. Older retirees have a higher share of their portfolio in bonds, a higher share in risky assets, a lower share in annuities, and a higher share in housing. Healthier retirees have a higher share of their portfolio in bonds, a higher share in risky assets, a lower share in annuities, and a higher share in housing 3

For ease of comparison to the model in later analysis, Figure 2 plots the portfolio shares in each of the four assets as a function of age and health status. The predicted portfolio shares are those for the 1931-1940 cohort. Retirees allocate a significant share of their wealth to bonds and risky assets, even late in the retirement cycle. This fact has been attributed to both a bequest motive and a precautionary saving motive in response to health uncertainty.

Housing remains a significant share of the portfolio, even late in the retirement cycle. Venti and Wise $(1989,2004)$ find that retirees are unlikely to discontinue home ownership, and on average, increase their home equity when they move. Based on this evidence, Venti and Wise conclude that the large home equity in the retirement portfolio is not a consequence of transactions costs that prevent retirees from downsizing their homes.

\section{Benchmark Calibration of the Model}

\subsection{Calibration of Preferences}

Table 6 summarizes the key parameters in the benchmark calibration. Following a standard practice in the life-cycle consumption and portfolio-choice literature, I set the subjective

\footnotetext{
${ }^{3}$ Hurd (2002) and Coile and Milligan (2006) also document asset allocation in the HRS, but they ignore the asset value of annuities in their analysis. Rosen and Wu (2004) document evidence that the portfolio share in risky assets is positively related to health.
} 
discount factor to $\beta=0.96$. Because of the large premium on risky assets, the relative risk aversion must be fairly large in order to match the asset allocation between bonds and risky assets. I therefore set $\gamma=6$. These choices are consistent with the structural estimates in De Nardi, French, and Jones (2006).

If $\rho<1 / \gamma$, consumption and health are complements in the sense that the marginal utility of consumption rises in the health stock. If $\rho>1 / \gamma$, consumption and health are substitutes. Introspection suggests that consumption and health must be complements at an extremely low level of health stock that approaches death. Viscusi and Evans (1990) analyze a survey of chemical workers and find that consumption and health are complements. Based on this evidence, I set the elasticity of substitution to $\rho=0.1$. As discussed below, I calibrate the remaining preference parameters to match certain empirical moments describing health accumulation and asset allocation.

I discretize the health stock as a grid over five values, corresponding to the five categories of health status. I normalize the initial distribution of health at age $65-66$ so that $\log H_{1} \sim$ $\mathbf{N}(0,1)$. By inverting the lognormal distribution function, I obtain the health stock for each category of health status, which are reported in Table 6 .

\subsection{Consumption and Portfolio Policy}

I solve the model through numerical dynamic programming as described in Appendix A. In each period $t$, the state variables of the consumption and portfolio-choice problem are total wealth $\widetilde{W}_{t}$, initial annuity holdings $B_{0}$, and the relative price of housing $P_{t}$. For the purposes of solving the problem, it is convenient to replace total wealth with the health stock $H_{t}$ as a state variable.

Figure 3 shows the consumption policy function, as a share of total wealth, at age 6566. Holding initial annuity holdings constant, the retiree consumes a higher share of total wealth when she is healthier. This result is due to the fact that consumption and health are complements in the retiree's utility function. 
Figure 3 also shows the portfolio policy functions, as a share of total savings, at age 65-66. The policy functions for bonds and risky assets mirror that for the annuity. At high health and low initial annuity holdings, the portfolio shares in bonds and risky assets are high. At low health and high initial annuity holdings, the portfolio share in the annuity is high. When the retiree cannot purchase additional units of the annuity, she holds a portfolio of bonds and risky assets as an imperfect substitute to insure against longevity risk.

\subsection{Distribution of Health Status}

In order to calibrate the model, it is useful to first document the cross-sectional distribution of health status in the HRS. I use an ordered probit model to estimate the distribution of health status as a function of cohort dummies and age. The left panel of Figure 4 plots the cross-sectional distribution of health status by age for the 1931-1940 cohort.

Using the optimal consumption and portfolio policies, I simulate a population of retirees from age 65-66 to death. In the simulation, I set the initial distribution of health status at age 65-66 to exactly match the empirical distribution of health status. By varying the initial annuity holdings, it is possible to generate cross-sectional variation in financial wealth that is independent of health. However, I abstract from this additional source of cross-sectional heterogeneity and focus on the unconditional relation between portfolio choice and health. Insofar as health and wealth are highly correlated in the data, the absence of variation in wealth that is independent of health is a reasonable restriction of the simulated model. Appendix A contains further details on the simulation.

The parameter $\alpha$ plays a role in determining the share of health in the retiree's portfolio, and consequently, the accumulation of health over the retirement cycle. A higher value of $\alpha$ implies greater accumulation in health. I calibrate this parameter to match, as closely as

possible, the cross-sectional distribution of health status at age 91-92. The right panel of Figure 4 plots the cross-sectional distribution of health status at each age for the simulated model. 


\subsection{Asset Allocation of Simulated Retirees}

Figure [5]shows the asset allocation of simulated retirees as a function of age and health status. The figure compares favorably to that of actual retirees in the HRS, shown in Figure2. With a limited set of parameters, it is impossible to match all the empirical moments describing asset allocation. I therefore focus on those at the beginning of retirement, at age 65-66, and those at the end of retirement, at age 91-92. For ease of comparison to the data, Table 7 reports the portfolio shares in each of the four tangible assets at age 65-66. Table 8 reports the same at age $91-92$.

For each health status, I calibrate the initial annuity holdings $B_{0}$ to match the portfolio share in annuity at age 65-66. Upon death, the retiree leaves behind only bonds, risky assets, and housing. Therefore, the bequest motive plays a key role in determining the portfolio share in annuity as the retiree approaches death. I choose the value $\bar{u}=0.17$ to match the portfolio share in annuity for the median-health retiree at age 91-92.

In the model, housing is an attractive asset because the retiree can enjoy its utility flow while alive and also leave it as a bequest. The parameter $\phi$ plays a key role in determining the portfolio share in housing. I choose the value $\phi=0.1$ to match the portfolio share in housing for the median-health retiree at age 91-92.

One potentially important feature of housing that is from missing from the model is illiquidity, that there may be transactions costs involved in selling the house 4 Transactions costs would make liquid assets, such as bonds and risky assets, more attractive relative to housing. Although this extension can change the relative asset allocation between bonds, risky assets, and housing, the overall level of precautionary savings in these assets should not be affected.

\footnotetext{
${ }^{4}$ See Cocco (2005), Hu (2005), and Yao and Zhang (2005) for an analysis of housing and portfolio choice with transactions costs.
} 


\subsection{Importance of the Bequest Motive}

In order to assess the importance of the bequest motive, I solve the model without a bequest motive, setting the parameter $\bar{u}=\infty$. I keep the other parameters of the model the same as those in the benchmark calibration. Figure 6 shows the asset allocation of simulated retirees as a function of age and health status. A comparison to Figure 5 shows that the absence of a bequest motive drastically alters the retirement portfolio. In addition to her endowment in the annuity, a healthy retiree holds mostly risky assets and housing. An unhealthy retiree holds mostly housing. Most retirees hold a small short position in bonds, representing a loan against their home equity.

This analysis shows that the bequest motive is the primary reason that retirees hold bonds and risky assets. This finding is in contrast to earlier work that emphasized a precautionary motive driven by uncertain health expenditures (Hubbard, Skinner, and Zeldes 1994, Palumbo 1999, De Nardi, French, and Jones 2006). The conclusions of the earlier work relied on the assumption that health expenditures are exogenous and unavoidable. When health expenditures are endogenized as investments in health, the precautionary motive to save in liquid assets essentially disappears. This is because the retiree can invest directly in health by accumulating health capital, rather than indirectly by accumulating liquid assets.

\section{Welfare Analysis of an Actuarially Fair Annuity Mar- ket}

In the analysis so far, the retiree is constrained to hold a constant endowment of the annuity throughout retirement. I now relax this constraint and allow the retiree to purchase additional units through an actuarially fair annuity market. In terms of the model, this amounts to relaxing the portfolio constraint on the annuity to be $B_{3 t} \geq B_{3, t-1}$.

Figure 7 shows the asset allocation of simulated retirees as a function of age and health status. A comparison to Figure 5 shows that the presence of an actuarially fair annuity 
market causes a relatively small change in the retirement portfolio. The biggest change occurs for retirees in excellent health, who substitute bonds with the annuity.

How much additional wealth does a retiree require at age 65 to achieve the same level of expected utility over retirement as in a hypothetical world with an actuarially fair annuity market? I evaluate the welfare gains of an annuity market by comparing the solution in the benchmark model with that in the model with an actuarially fair annuity market. The welfare gains, as a percentage of initial wealth in the benchmark model, is $0 \%$ for retirees in poor or fair health, $0.1 \%$ for retirees in good health, $8.6 \%$ for retirees in very good health, and $10.4 \%$ for retirees in excellent health.

This calculation should be considered an upper bound on the welfare gains from a private annuity market. Because of adverse selection and transactions costs, the private annuity market offers a lower rate of return than an actuarially fair annuity market based on So-

cial Security life tables and the Treasury bond rate (Warshawsky 1988, Mitchell, Poterba, Warshawsky, and Brown 1999). Because the welfare gain is small except for the healthiest retirees, the lack of demand in the private annuity market is less of a puzzle.

\section{Conclusion}

In a model with uncertainly only over the time of death, Friedman and Warshawsky (1990) showed that a bequest motive is necessary to explain the lack of annuitization, especially late in the retirement cycle. The subsequent literature argued that uncertainty over health expenditures can explain the lack of annuitization, even in the absence of a bequest motive. By endogenizing health accumulation, this paper has shown that previous studies, based on a model with exogenous health expenditures, overstate the importance of the precautionary motive to save in liquid assets. In a world with endogenous health accumulation, the retiree can invest directly in health capital through health expenditures, rather than indirectly by holding liquid assets. Consequently, a fairly strong bequest motive is necessary to explain the 
lack of annuitization, more consistent with the earlier findings of Friedman and Warshawsky.

I calibrate the consumption and portfolio-choice model to match the joint evolution of health status and the composition of wealth for retired unmarried females, aged 65 to 96 , in the HRS. I then use the calibrated model to assess the welfare gains from an actuarially fair annuity market. The welfare gain is fairly small for most retirees, and even for healthiest, the welfare gain is only about $10 \%$ of wealth at age 65 . Because the implicit holdings of annuities through defined benefit pension plans and Social Security are already large, the low demand for private annuities is a rational choice for the median-health retiree. A policy implication of the findings is that retirees, especially those in poor health whose expected horizon is short, should be allowed to receive some of their Social Security benefits in lump sum, rather than as an annuity (see Brown, Casey, and Mitchell (2007) for supportive survey evidence).

There are several issues that I have not examined, which are worth addressing in future work. First, the model should be extended to encompass married households, in which consumption and portfolio choice depends on the health and survival of the spouse (Lillard and Weiss 1997, Jacobson 2000, Love 2008). Second, the horizon should be extended to include the working life before retirement. Both health status and access to health insurance can affect the timing of retirement, and consequently, consumption and portfolio decisions 5 Finally, the model can be used to assess the welfare implications of other retirement financial products, such as variable annuities and reverse mortgages.

\footnotetext{
${ }^{5}$ Bound (1991), Bound, Schoenbaum, Stinebrickner, and Waidmann (1999), Dwyer and Mitchell (1999), and McGarry (2004) provide evidence on the relation between retirement and health status. Madrian (1994) and Rogowski and Karoly (2000) provide evidence, and French and Jones (2004) and Blau and Gilleskie (2003) develop models, on the relation between retirement and health insurance.
} 


\section{Appendix A Solution of the Consumption and Portfolio- Choice Problem}

\section{A.1 Rescaling the Model by Total Wealth}

Because the utility function is homothetic, it is convenient to rescale the consumption and

portfolio-choice model by total wealth. Define rescaled consumption as $c_{t}=C_{t} / \widetilde{W}_{t}$. For each asset $i=1, \ldots, N, D, H$, define the portfolio share of total savings as $a_{i t}=A_{i t} /\left(\widetilde{W}_{t}-C_{t}\right)$.

The intraperiod budget constraint (11) can be rewritten as

$$
\sum_{i=1}^{N} a_{i t}+a_{D t}+a_{H t}=1
$$

The intertemporal budget constraint (14) can be rewritten as

$$
\frac{\widetilde{W}_{t+1}}{\widetilde{W}_{t}}=R_{t+1}\left(1-c_{t}\right)
$$

where

$$
R_{t+1}=\sum_{i=1}^{N} a_{i t} R_{i, t+1}+a_{D t} R_{D, t+1}+a_{H t} R_{H, t+1}
$$

is the gross rate of return on total wealth.

In the model with an actuarially fair annuity market, the portfolio constraints are

$$
\begin{aligned}
& a_{1 t} \in\left[-\lambda a_{D t}, 1-a_{D t}-a_{H t}\right], \\
& a_{2 t} \in\left[0,1-a_{D t}-a_{H t}\right], \\
& a_{3 t} \in\left[\frac{P_{3 t} B_{3, t-1}}{\widetilde{W}_{t}\left(1-c_{t}\right)}, 1-a_{D t}-a_{H t}\right], \\
& a_{D t} \in\left[0, \frac{1}{1-\lambda}\right], \\
& a_{H t} \in[0,1] .
\end{aligned}
$$


In the benchmark model without an annuity market, the lower bound on portfolio constraint (30) is binding. Portfolio constraint (28) and the intraperiod budget constraint can be combined as an inequality constraint,

$$
a_{2 t}+a_{3 t}+(1-\lambda) a_{D t}+a_{H t} \leq 1 .
$$

Define rescaled utility as

$$
u_{t}\left(c_{t}, a_{D t}, a_{H t}\right)=c_{t} V_{t}\left(c_{t}, a_{D t}, a_{H t}\right),
$$

where

$$
V_{t}\left(c_{t}, a_{D t}, a_{H t}\right)=\left[(1-\alpha)\left(\frac{a_{D t}\left(c_{t}^{-1}-1\right)}{P_{t}}\right)^{\phi(1-1 / \rho)}+\alpha\left(\frac{a_{H t}\left(c_{t}^{-1}-1\right)}{Q_{t}}\right)^{1-1 / \rho}\right]^{1 /(1-1 / \rho)} .
$$

The marginal utility of consumption is

$$
\frac{\partial u_{t}}{\partial c_{t}}=V_{t}-\frac{V_{t}^{1 / \rho}}{1-c_{t}}\left[(1-\alpha) \phi\left(\frac{a_{D t}\left(c_{t}^{-1}-1\right)}{P_{t}}\right)^{\phi(1-1 / \rho)}+\alpha\left(\frac{a_{H t}\left(c_{t}^{-1}-1\right)}{Q_{t}}\right)^{1-1 / \rho}\right] .
$$

The marginal utility of the portfolio share in housing is

$$
\frac{\partial u_{t}}{\partial a_{D t}}=\frac{(1-\alpha) \phi c_{t} V_{t}^{1 / \rho}}{a_{D t}}\left(\frac{a_{D t}\left(c_{t}^{-1}-1\right)}{P_{t}}\right)^{\phi(1-1 / \rho)} .
$$

The marginal utility of the portfolio share in health is

$$
\frac{\partial u_{t}}{\partial a_{H t}}=\frac{\alpha c_{t} V_{t}^{1 / \rho}}{a_{H t}}\left(\frac{a_{H t}\left(c_{t}^{-1}-1\right)}{Q_{t}}\right)^{1-1 / \rho} .
$$

Let $a_{t}=\left\{a_{2 t}, \ldots, a_{N t}, a_{D t}, a_{H t}\right\}$ be the set of portfolio shares for all assets, including 
housing and health. The value function (16) can be rescaled as

$$
\begin{aligned}
j_{t}=\frac{J_{t}\left(\widetilde{W}_{t}\right)}{\widetilde{W}_{t}^{1-\gamma}}= & \max _{c_{t}, a_{t}} \frac{u_{t}\left(c_{t}, a_{D t}, a_{H t}\right)^{1-\gamma}}{1-\gamma} \\
& +\beta \mathbf{E}_{t}\left[R_{t+1}^{1-\gamma}\left(1-c_{t}\right)^{1-\gamma}\left(1\left\{\omega_{t+1}<1\right\} j_{t+1}+1\left\{\omega_{t+1}=1\right\} \frac{\bar{u}^{1-\gamma}}{1-\gamma}\right)\right] .
\end{aligned}
$$

The derivative of the value function with respect to consumption is

$$
\frac{\partial j_{t}}{\partial c_{t}}=u_{t}^{-\gamma} \frac{\partial u_{t}}{\partial c_{t}}-\beta(1-\gamma) \mathbf{E}_{t}\left[R_{t+1}^{1-\gamma}\left(1-c_{t}\right)^{-\gamma}\left(1\left\{\omega_{t+1}<1\right\} j_{t+1}+1\left\{\omega_{t+1}=1\right\} \frac{\bar{u}^{1-\gamma}}{1-\gamma}\right)\right] .
$$

The derivatives of the value function with respect to the portfolio shares in financial assets are

$$
\begin{aligned}
\frac{\partial j_{t}}{\partial a_{i t}}= & \beta(1-\gamma) \mathbf{E}_{t}\left[R_{t+1}^{-\gamma}\left(R_{i, t+1}-R_{1, t+1}\right)\left(1-c_{t}\right)^{1-\gamma}\right. \\
& \left.\times\left(1\left\{\omega_{t+1}<1\right\} j_{t+1}+1\left\{\omega_{t+1}=1\right\} \frac{\bar{u}^{1-\gamma}}{1-\gamma}\right)\right],
\end{aligned}
$$

for $i=2, \ldots, N$. The derivative of the value function with respect to the portfolio share in housing is

$$
\begin{aligned}
\frac{\partial j_{t}}{\partial a_{D t}}= & u_{t}^{-\gamma} \frac{\partial u_{t}}{\partial a_{D t}}+\beta(1-\gamma) \mathbf{E}_{t}\left[R_{t+1}^{-\gamma}\left(R_{D, t+1}-R_{1, t+1}\right)\left(1-c_{t}\right)^{1-\gamma}\right. \\
& \left.\times\left(1\left\{\omega_{t+1}<1\right\} j_{t+1}+1\left\{\omega_{t+1}=1\right\} \frac{\bar{u}^{1-\gamma}}{1-\gamma}\right)\right] .
\end{aligned}
$$

Finally, the derivative of the value function with respect to the portfolio share in health is

$$
\begin{aligned}
\frac{\partial j_{t}}{\partial a_{H t}}= & u_{t}^{-\gamma} \frac{\partial u_{t}}{\partial a_{H t}}+\beta(1-\gamma) \mathbf{E}_{t}\left[R_{t+1}^{-\gamma}\left(R_{H, t+1}-R_{1, t+1}\right)\left(1-c_{t}\right)^{1-\gamma}\right. \\
& \left.\times\left(1\left\{\omega_{t+1}<1\right\} j_{t+1}+1\left\{\omega_{t+1}=1\right\} \frac{\bar{u}^{1-\gamma}}{1-\gamma}\right)\right] .
\end{aligned}
$$




\section{A.2 Solution in the Last Period with No Bequest Motive}

A special case of the model is when the retiree has no bequest motive, which corresponds to the parameterization $\bar{u}=\infty$. In this case, the policy functions in the last period can be derived in closed form. This known solution serves as a useful starting point for numerically computing the solution when the retiree has a bequest motive.

The value function in the last period $T$ is

$$
j_{T}=\max _{c_{T}, a_{T}} \frac{u_{T}\left(c_{T}, a_{D T}, a_{H T}\right)^{1-\gamma}}{1-\gamma} .
$$

Because it is optimal to consume all financial wealth, the optimal portfolio shares in financial assets are

$$
\begin{aligned}
& a_{1 T}=-\lambda a_{D T}, \\
& a_{2 T}=0, \\
& a_{3 T}=\left(Z_{T}-1\right) a_{H T},
\end{aligned}
$$

where $Z_{T}=1+P_{3 T} B_{3, T-1} /\left(Q_{T} H_{T}\right)$.

The problem is now reduced to that of maximizing the value function, subject to the constraint

$$
(1-\lambda) a_{D T}+Z_{T} a_{H T}=1 .
$$


The first-order conditions imply that

$$
\begin{aligned}
c_{T} & =\frac{(1-\phi)\left(1-Z_{T} a_{H T}\right)}{1-(1-\phi) Z_{T} a_{H T}} \\
a_{D T} & =\frac{1-Z_{T} a_{H T}}{1-\lambda} \\
a_{H T} & =\left[Z_{T}+\frac{\phi^{1-\phi(1-\rho)}}{(1-\phi)^{(1-\phi)(1-\rho)}}\left(\frac{(1-\alpha) Z_{T}}{\alpha}\right)^{\rho}\left(\frac{(1-\lambda)^{\phi} P_{T}^{\phi}}{Q_{T}}\right)^{1-\rho}\right]^{-1} .
\end{aligned}
$$

\section{A.3 Solution by Numerical Dynamic Programming}

I discretize the state space as

$$
\begin{aligned}
\left\{H_{j}\right\}_{j=1}^{J} & =\left\{H_{P}, H_{F}, H_{G}, H_{V G}, H_{E}\right\} \\
\left\{B_{k}\right\}_{k=1}^{K} & =\left\{B_{1}, \ldots, B_{K}\right\} \\
\left\{P_{l}\right\}_{l=1}^{L} & =\left\{P_{1}, \ldots, P_{L}\right\} .
\end{aligned}
$$

Table 6 reports the grid for the health stock. The grid for annuity holdings is equally spaced on a logarithmic scale, based on $K=20, B_{1}=0.1$, and $B_{K}=5$. The grid for the relative price of housing is equally spaced on a logarithmic scale, based on $L=5, P_{1}=1$, and $P_{L}=5$. I discretize the lognormal shock to risky assets, $\nu_{2 t}$, through five realizations with equal probability.

Starting with the solution in period $T$, I solve the problem recursively for periods $t=$ $T-1, \ldots, 1$ through the following algorithm.

1. For each point on the discretized state space, find the policy functions that maximize the value function $j_{t}\left(H_{j}, B_{k}, P_{l}\right)$.

2. Compute the total wealth corresponding to the optimal portfolio share in health 
through the relation

$$
\widetilde{W}_{t}\left(H_{j}, B_{k}, P_{l}\right)=\frac{Q_{t}\left(H_{j}\right) H_{j}}{a_{H t}\left(H_{j}, B_{k}, P_{l}\right)\left(1-c_{t}\left(H_{j}, B_{k}, P_{l}\right)\right)} .
$$

\section{A.4 Simulation of the Model}

I simulate the retirement cycle for 100,000 retirees, starting at age 65-66. I set the initial price of housing at $P_{1}=1$ for all retirees. The initial distribution of health status is drawn from the empirical distribution of health status at age 65-66 for the 1931-1940 cohort. For

each category of health status, $H_{1}=\left\{H_{P}, H_{F}, H_{G}, H_{V G}, H_{E}\right\}$, I compute $B_{0}\left(H_{1}\right)$ such that

$$
\frac{a_{31}\left(H_{1}, B_{0}\left(H_{1}\right), P_{1}\right)}{1-a_{H 1}\left(H_{1}, B_{0}\left(H_{1}\right), P_{1}\right)}
$$

matches the portfolio share in the annuity, as a share of tangible wealth, in the HRS at age 65-66.

For periods $t=2, \ldots, T$, I simulate the retirement cycle for each retiree, until death, through the following algorithm.

1. Simulate the shocks to risky asset returns, housing returns, and the health stock. Compute the gross return on total wealth,

$$
R_{t}=\sum_{i=1}^{3} a_{i, t-1} R_{i t}+a_{D, t-1} R_{D t}+a_{H, t-1} R_{H t}
$$

2. Update the total wealth through the relation

$$
\widetilde{W}_{t}=R_{t} \frac{Q_{t-1} H_{t-1}}{a_{H, t-1}}
$$

3. If there is an actuarially fair annuity market, update the annuity holdings through the 
relation

$$
B_{t-1}=\frac{a_{3, t-1} Q_{t-1} H_{t-1}}{P_{3, t-1} a_{H, t-1}} .
$$

4. Update the health stock through a closest neighbor interpolation of $H_{t}$ as a function of $\widetilde{W}_{t}\left(H_{t}, B_{t-1}, P_{t}\right)$.

5. Compute the optimal consumption and portfolio policies at the state $\left(H_{t}, B_{t-1}, P_{t}\right)$. 


\section{References}

Abel, Andrew B., and Mark Warshawsky, 1988, Specification of the joy of giving: Insights from altruism, Review of Economics and Statistics 70, 145-149.

Ameriks, John, Andrew Caplin, Steven Laufer, and Stijn Van Nieuwerburgh, 2007, The joy of giving or assisted living? Using strategic surveys to separate bequest and precautionary motives, Working paper, New York University.

Bell, Felicitie C., and Michael L. Miller, 2005, Life tables for the United States Social Security area 1900-2100, Actuarial Study No. 120, Social Security Administration.

Blau, David M., and Donna B. Gilleskie, 2003, The role of retiree health insurance in the employment behavior of older men, Working Paper No. 10100, National Bureau of Economic Research.

Bound, John, 1991, Self-reported versus objective measures of health in retirement models, Journal of Human Resources 26, 106-138.

Bound, John, Michael Schoenbaum, Todd R. Stinebrickner, and Timothy Waidmann, 1999, The dynamic effects of health on the labor force transitions of older workers, Labour Economics 6, 179-202.

Brown, Jeffrey R., Marcus D. Casey, and Olivia S. Mitchell, 2007, Who values the Social Security annuity? New evidence on the annuity puzzle, Working paper, University of Illinois at Urbana-Champaign.

Cocco, João F., 2005, Portfolio choice in the presence of housing, Review of Financial Studies $18,535-567$.

Cocco, João F., Francisco J. Gomes, and Pascal J. Maenhout, 2005, Consumption and portfolio choice over the life cycle, Review of Financial Studies 18, 491-533. 
Coile, Courtney C., and Kevin S. Milligan, 2006, How household portfolios evolve after retirement: The effect of aging and health shocks, Working Paper No. 12391, National Bureau of Economic Research.

Davidoff, Thomas, Jeffrey R. Brown, and Peter A. Diamond, 2005, Annuities and individual welfare, American Economic Review 95, 1573-1590.

De Nardi, Mariacristina, Eric French, and John Bailey Jones, 2006, Differential mortality, uncertain medical expenditures, and the savings of elderly singles, Working Paper No. 12554, National Bureau of Economic Research.

Dwyer, Debra Sabatini, and Olivia S. Mitchell, 1999, Health problems as determinants of retirement: Are self-rated measures endogenous?, Journal of Health Economics 18, 173193.

Edwards, Ryan D., 2005, Health risk and portfolio choice, Working paper, RAND Corporation.

French, Eric, and John Bailey Jones, 2004, The effects of health insurance and self-insurance on retirement behavior, Working paper, Federal Reserve Bank of Chicago.

Friedman, Benjamin M., and Mark J. Warshawsky, 1990, The cost of annuities: Implications for saving behavior and bequests, Quarterly Journal of Economics 105, 135-54.

Grossman, Michael, 1972, On the concept of health capital and the demand for health, Journal of Political Economy 80, 223-255.

Gustman, Alan L., Olivia S. Mitchell, Andrew A. Samwick, and Thomas L. Steinmeier, 1997, Pension and Social Security wealth in the Health and Retirement Study, Working Paper No. 5912, National Bureau of Economic Research.

Hu, Xiaoqing, 2005, Portfolio choices for homeowners, Journal of Urban Economics 58, $114-136$. 
Hubbard, R. Glenn, Jonathan Skinner, and Stephen P. Zeldes, 1994, The importance of precautionary motives in explaining individual and aggregate saving, Carnegie-Rochester Conference Series on Public Policy 40, 59-125.

Hurd, Michael D., 2002, Portfolio holdings of the elderly, in Luigi Guiso, Michael Haliassos, and Tullio Jappelli, ed.: Household Portfolios . chap. 11, pp. 431-472 (MIT Press: Cambridge, MA).

Jacobson, Lena, 2000, The family as producer of health - an extended Grossman model, Journal of Health Economics 19, 611-637.

Khwaja, Ahmed W., 2002, Health insurance, habits and health outcomes: Moral hazard in a dynamic stochastic model of investment in health, Working paper, Duke University.

Lillard, Lee A., and Yoram Weiss, 1997, Uncertain health and survival: Effects on end-of-life consumption, Journal of Business and Economic Statistics 15, 254-268.

Love, David A., 2008, Marital status and portfolio choice, Working paper, Williams College.

Love, David A., and Maria G. Perozek, 2007, Should the old play it safe? Portfolio choice with uncertain medical expenses, Working paper, Williams College.

Madrian, Brigitte C., 1994, The effect of health insurance on retirement, Brookings Papers on Economic Activity 1, 181-232.

McGarry, Kathleen, 2004, Health and retirement: Do changes in health affect retirement expectations?, Journal of Human Resources 39, 624-648.

Mitchell, Olivia S., James M. Poterba, Mark J. Warshawsky, and Jeffrey R. Brown, 1999, New evidence on the money's worth of individual annuities, American Economic Review 89, 1299-1318.

Palumbo, Michael G., 1999, Uncertain medical expenses and precautionary saving near the end of the life cycle, Review of Economic Studies 66, 395-421. 
Pang, Gaobo, and Mark Warshawsky, 2007, Optimizing the equity-bond-annuity portfolio in retirement: The impact of uncertain health expenses, Technical Paper No. 07/14, Watson Wyatt Worldwide.

Picone, Gabriel, Martin Uribe, and R. Mark Wilson, 1998, The effect of uncertainty on the demand for medical care, health capital and wealth, Journal of Health Economics 17, $171-185$.

Rogowski, Jeannette, and Lynn Karoly, 2000, Health insurance and retirement behavior: Evidence from the Health and Retirement Survey, Journal of Health Economics 19, 529539.

Rosen, Harvey S., and Stephen Wu, 2004, Portfolio choice and health status, Journal of Financial Economics 72, 457-484.

Sinai, Todd, and Nicholas S. Souleles, 2007, Net worth and housing equity in retirement, Working Paper No. 13693, National Bureau of Economic Research.

Turra, Cassio M., and Olivia S. Mitchell, 2004, The impact of health status and out-of-pocket medical expenditures on annuity valuation, Working paper, University of Pennsylvania.

Venti, Steven F., and David A. Wise, 1989, Aging, moving, and housing wealth, in David A. Wise, ed.: The Economics of Aging . chap. 1, pp. 9-48 (The University of Chicago Press: Chicago).

Venti, Steven F., and David A. Wise, 2004, Aging and housing equity: Another look, in David A. Wise, ed.: Perspectives on the Economics of Aging . chap. 3, pp. 127-175 (The University of Chicago Press: Chicago).

Viscusi, W. Kip, and William N. Evans, 1990, Utility functions that depend on health status: Estimates and economic implications, American Economic Review 80, 353-374. 
Wagstaff, Adam, 1986, The demand for health: Some new empirical evidence, Journal of Health Economics 5, 195-233.

Wallace, Robert B., and A. Regula Herzog, 1995, Overview of the health measures in the Health and Retirement Study, Journal of Human Resources 30, 84-107.

Warshawsky, Mark, 1988, Private annuity markets in the United States: 1919-1984, Journal of Risk and Insurance 55, 518-528.

Yaari, Menahem E., 1965, Uncertain lifetime, life insurance, and the theory of the consumer, Review of Economic Studies 32, 137-150.

Yao, Rui, and Harold H. Zhang, 2005, Optimal consumption and portfolio choices with risky housing and borrowing constraints, Review of Financial Studies 18, 197-239. 
Table 1: Health Expenditure by Age and Health Status

The table reports the median of health expenditures by age and health status. Health expenditures are annualized, deflated by the CPI for medical care, and reported in real 2000 dollars. Health expenditures include the cost of hospitals, nursing homes, doctor visits, dentist visits, outpatient surgery, prescription drugs, home health care, and special facilities. The sample consists of retired unmarried females, born 1901 to 1940 and aged 65 to 96, in the HRS.

\begin{tabular}{lrrrr}
\hline Health Status & \multicolumn{4}{c}{ Age } \\
\cline { 2 - 5 } & $65-72$ & $73-80$ & $81-88$ & $89-96$ \\
\hline \multicolumn{2}{c}{ Panel A: Total Health } & Expenditure (\$ per Year) \\
\hline Poor & 7,813 & 5,145 & 4,127 & 4,622 \\
Fair & 2,745 & 2,976 & 3,324 & 2,943 \\
Good & 2,191 & 2,273 & 2,419 & 2,273 \\
Very Good & 902 & 1,243 & 1,264 & 1,484 \\
Excellent & 904 & 851 & 604 & 1,353 \\
All Retirees & 2,141 & 2,273 & 2,500 & 2,399 \\
\hline Panel B: Out-of-Pocket & Health Expenditure (\$ per Year) \\
\hline Poor & 920 & 768 & 864 & 853 \\
Fair & 636 & 709 & 722 & 805 \\
Good & 502 & 594 & 609 & 656 \\
Very Good & 360 & 449 & 426 & 450 \\
Excellent & 400 & 237 & 302 & 567 \\
All Retirees & 480 & 551 & 582 & 646 \\
\hline
\end{tabular}


Table 2: Health Care Utilization Rates by Age and Health Status

The table reports the percentage of retirees, by age and health status, utilizing the indicated health care in the two years prior to the interview. The sample consists of retired unmarried females, born 1901 to 1940 and aged 65 to 96, in the HRS.

\begin{tabular}{|c|c|c|c|c|}
\hline \multirow[t]{2}{*}{ Health Status } & \multicolumn{4}{|c|}{ Age } \\
\hline & $\overline{65-72}$ & $73-80$ & $81-88$ & $89-96$ \\
\hline \multicolumn{5}{|c|}{ Panel A: Doctor and Dentist Visits (\% of Retirees) } \\
\hline Poor & 99 & 99 & 98 & 98 \\
\hline Fair & 98 & 98 & 98 & 97 \\
\hline Good & 98 & 98 & 97 & 96 \\
\hline Very Good & 95 & 97 & 96 & 97 \\
\hline Excellent & 97 & 95 & 89 & 87 \\
\hline All Retirees & 97 & 98 & 97 & 96 \\
\hline \multicolumn{5}{|c|}{$\begin{array}{l}\text { Panel B: Prescription Drugs (\% of Retirees) } \\
\text { (\% }\end{array}$} \\
\hline Poor & 97 & 95 & 93 & 96 \\
\hline Fair & 93 & 91 & 93 & 94 \\
\hline Good & 84 & 87 & 88 & 85 \\
\hline Very Good & 72 & 77 & 79 & 83 \\
\hline Excellent & 61 & 65 & 60 & 64 \\
\hline All Retirees & 81 & 84 & 86 & 87 \\
\hline \multicolumn{5}{|c|}{ Panel C: Hospitals and Oupatient Surgery (\% of Retirees) } \\
\hline Poor & 63 & 73 & 66 & 72 \\
\hline Fair & 52 & 53 & 59 & 49 \\
\hline Good & 41 & 46 & 46 & 48 \\
\hline Very Good & 25 & 33 & 40 & 40 \\
\hline Excellent & 25 & 28 & 33 & 26 \\
\hline All Retirees & 39 & 45 & 50 & 48 \\
\hline \multicolumn{5}{|c|}{$\begin{array}{l}\text { Panel D: Nursing Homes, Home Health Care, and Special Facilities (\% of Retirees) } \\
\text { (\% }\end{array}$} \\
\hline Poor & 43 & 47 & 55 & 56 \\
\hline Fair & 23 & 26 & 38 & 43 \\
\hline Good & 14 & 19 & 27 & 30 \\
\hline Very Good & 6 & 9 & 16 & 32 \\
\hline Excellent & 7 & 7 & 11 & 27 \\
\hline All Retirees & 16 & 20 & 30 & 37 \\
\hline
\end{tabular}


Table 3: Estimation of the Out-of-Pocket Health Expenditure Share The table reports estimates of a censored regression model for the out-of-pocket health expenditure share. The latent variable depends on cohort dummies, health status, age, and the interaction of health status with age. Health expenditures include the cost of hospitals, nursing homes, doctor visits, dentist visits, outpatient surgery, prescription drugs, home health care, and special facilities. The sample consists of retired unmarried females, born 1901 to 1940 and aged 65 to 96, in the HRS.

\begin{tabular}{lrr}
\hline Regressor & Coefficient & $t$-statistic \\
\hline Cohort: & & \\
1901-1910 & 0.00 & 0.09 \\
1911-1920 & -0.02 & -0.46 \\
1921-1930 & 0.00 & -0.07 \\
Health Status: & & \\
$\quad$ Poor & -0.19 & -4.18 \\
Fair & -0.06 & -1.81 \\
Very Good & 0.09 & 2.67 \\
Excellent & 0.07 & 1.56 \\
(Age - 65)/10 & 0.01 & 0.48 \\
$\quad$ × Poor & 0.04 & 1.36 \\
$\quad \times$ Fair & 0.01 & 0.60 \\
$\quad \times$ Very Good & -0.04 & -1.70 \\
$\quad \times$ Excellent & -0.07 & -2.09 \\
Intercept & 0.42 & 17.04 \\
\hline
\end{tabular}


Table 4: Estimation of the Transition Probabilities for Health Status

The table reports estimates of an ordered probit model for predicting health status in the subsequent period. The latent variable depends on cohort dummies, current health status, age, and the interaction of current health status with age. The latent variable also depends on log total health expenditure in the subsequent period, where expenditures below $\$ 500$ are truncated at $\$ 500$. The sample consists of retired unmarried females, born 1901 to 1940 and aged 65 to 96 , in the HRS.

\begin{tabular}{lrr}
\hline Regressor & Coefficient & $t$-statistic \\
\hline Cohort: & & \\
1901-1910 & -0.14 & -1.00 \\
1911-1920 & 0.04 & 0.44 \\
1921-1930 & 0.09 & 1.43 \\
Health Status: & & \\
Poor & -1.43 & -15.29 \\
Fair & -0.71 & -9.07 \\
Very Good & 0.83 & 10.07 \\
Excellent & 1.51 & 10.84 \\
(Age-65)/10 & -0.17 & -2.80 \\
× Poor & 0.18 & 2.54 \\
× Fair & 0.03 & 0.48 \\
$\quad \times$ Very Good & -0.16 & -2.48 \\
$\quad \times$ Excellent & -0.15 & -1.38 \\
Health Expenditure & 0.06 & 5.47 \\
Intercept: & & \\
Poor & -1.35 & -11.89 \\
Fair & -0.77 & -7.23 \\
Good & 0.05 & 0.45 \\
Very Good & 1.00 & 9.90 \\
Excellent & 2.13 & 20.38 \\
\hline
\end{tabular}




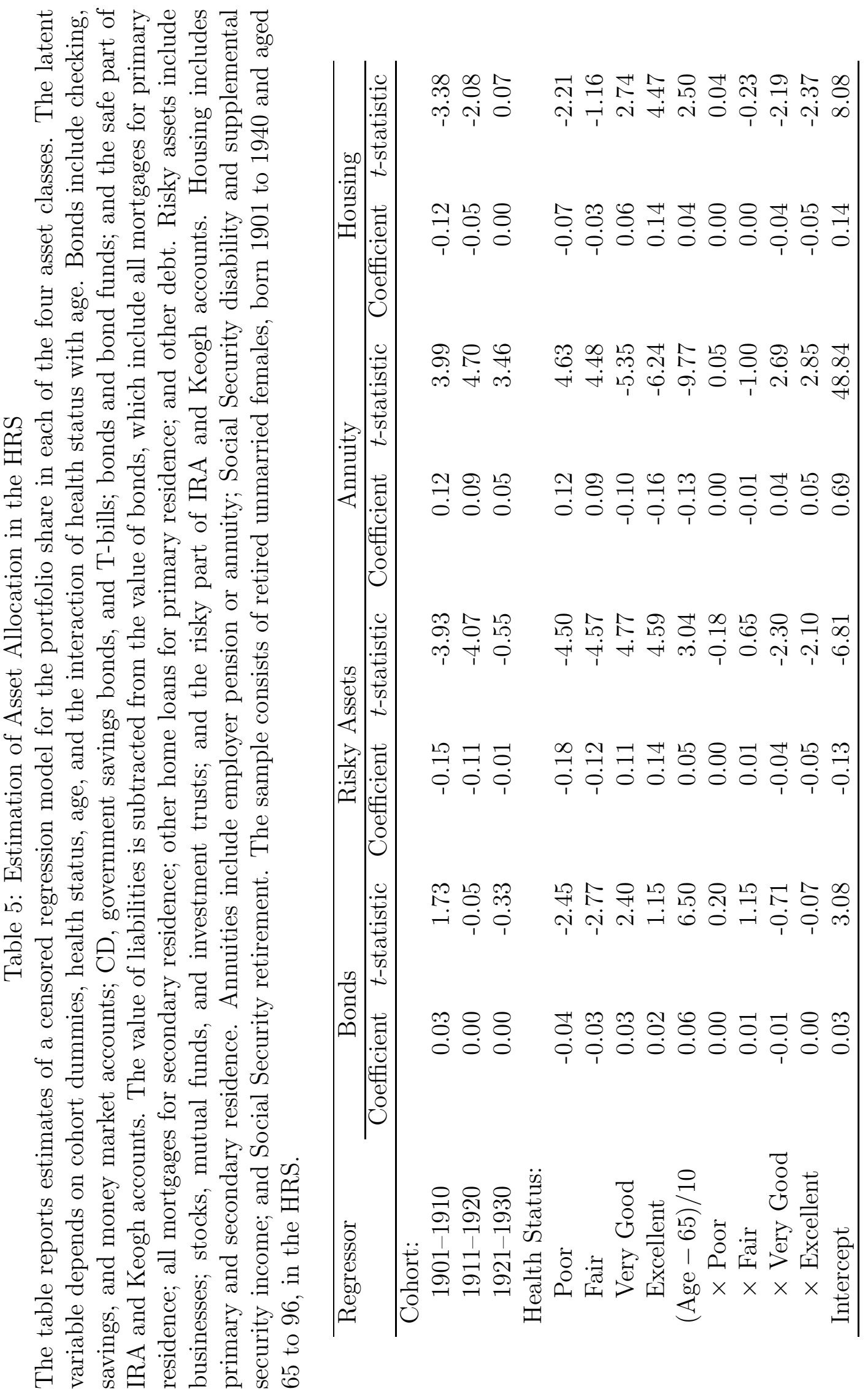


Table 6: Model Parameters in the Benchmark Calibration

The table summarizes the model parameters in the benchmark calibration. The model is solved at a two-year frequency to match the frequency of interviews in the HRS. The parameter values are reported in annualized units. The grid for the health stock is based on the normalization that the initial distribution of health at age $65-66$ is $\log H_{1} \sim \mathbf{N}(0,1)$.

\begin{tabular}{llr}
\hline Parameter & Symbol & Value \\
\hline Preferences: & \multicolumn{1}{l}{} \\
Discount factor & $\gamma$ & 0.96 \\
Relative risk aversion & $\phi$ & 6 \\
Utility weight on housing & $\alpha$ & 0.10 \\
Utility weight on health & $\rho$ & 0.90 \\
Elasticity of substitution between consumption and health & $\bar{u}$ & 0.17 \\
Joy-of-giving bequest motive & & \\
Asset returns: & $\bar{R}_{1}-1$ & $2.6 \%$ \\
Bond return & $\bar{R}_{2}-1$ & $5.6 \%$ \\
Average risky-asset return & $\sigma_{2}$ & $17.2 \%$ \\
Standard deviation of risky-asset return & $\bar{R}_{3}-1$ & $2.6 \%$ \\
Average annuity return & & \\
Housing: & $\lambda$ & $20 \%$ \\
Borrowing limit & $\delta$ & $1.14 \%$ \\
Depreciation rate & $\bar{R}_{D}-1$ & $2.2 \%$ \\
Average housing return & $\sigma_{D}$ & $7.0 \%$ \\
Standard deviation of housing return & & \\
Health: & $H_{P}$ & 0.18 \\
Poor health & $H_{F}$ & 0.42 \\
Fair health & $H_{G}$ & 0.90 \\
Good health & $H_{V G}$ & 1.99 \\
Very good health & $H_{E}$ & 5.06 \\
Excellent health & $q$ & $1.9 \%$ \\
Growth rate of the relative price of medical expenditure & $q$ &
\end{tabular}


Table 7: Asset Allocation of Simulated Retirees at Age 65-66

The table reports the portfolio share in each of the four tangible assets at age 65-66. From left to right, the columns correspond to actual retirees in the HRS, simulated retirees in the benchmark calibration, and simulated retirees in an economy with an actuarially fair annuity market. The portfolio shares for the HRS, based on the estimated censored regression model in Table 5, are those for the 1931-1940 cohort.

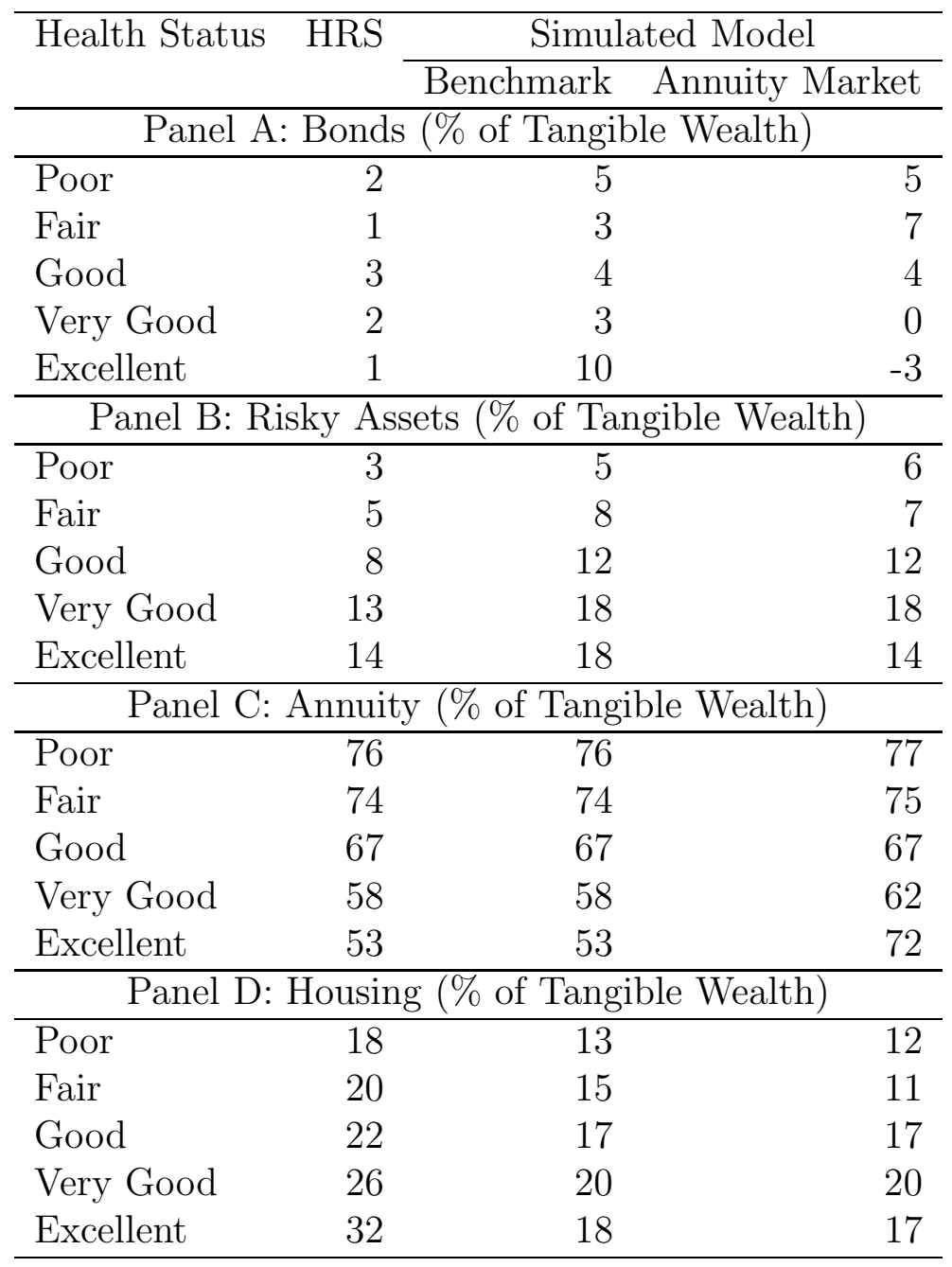


Table 8: Asset Allocation of Simulated Retirees at Age 91-92

The table reports the portfolio share in each of the four tangible assets at age 91-92. From left to right, the columns correspond to actual retirees in the HRS, simulated retirees in the benchmark calibration, and simulated retirees in an economy with an actuarially fair annuity market. The portfolio shares for the HRS, based on the estimated censored regression model in Table 5, are those for the 1931-1940 cohort.

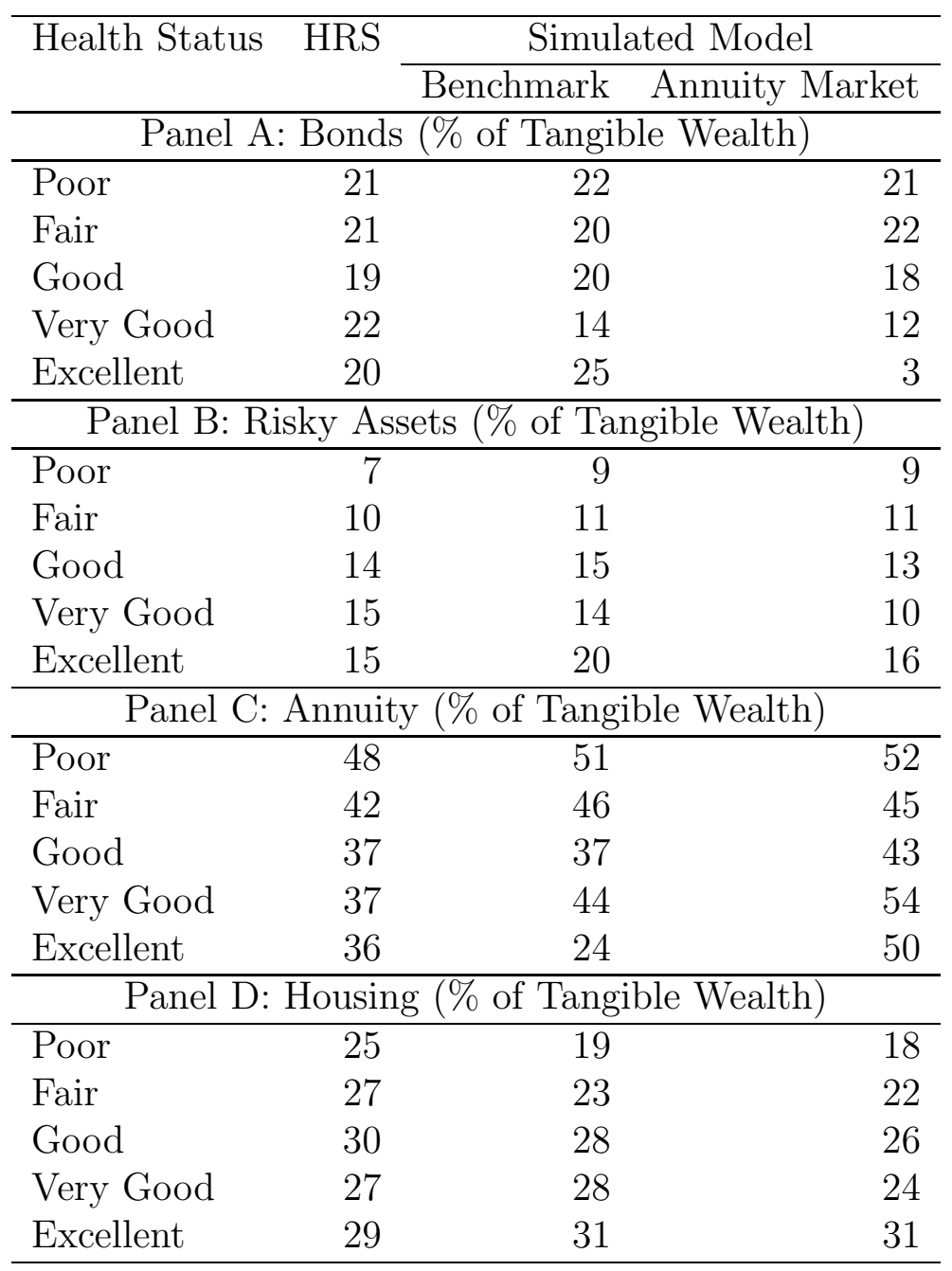




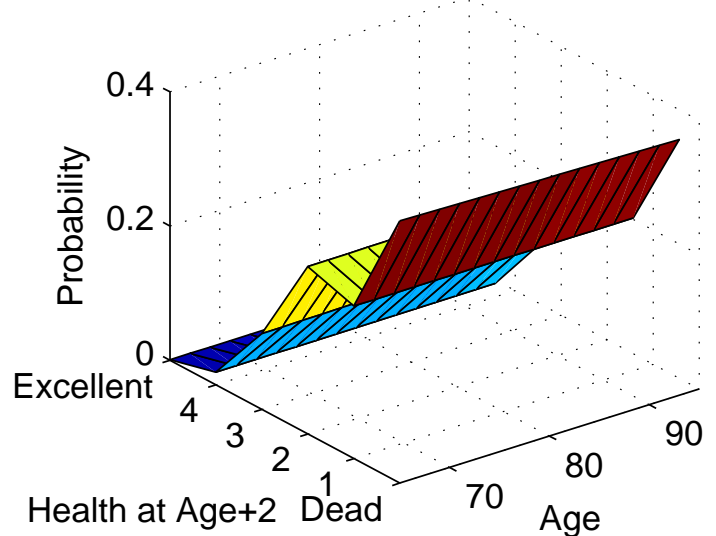

Conditional on Health $=3$ (Good)

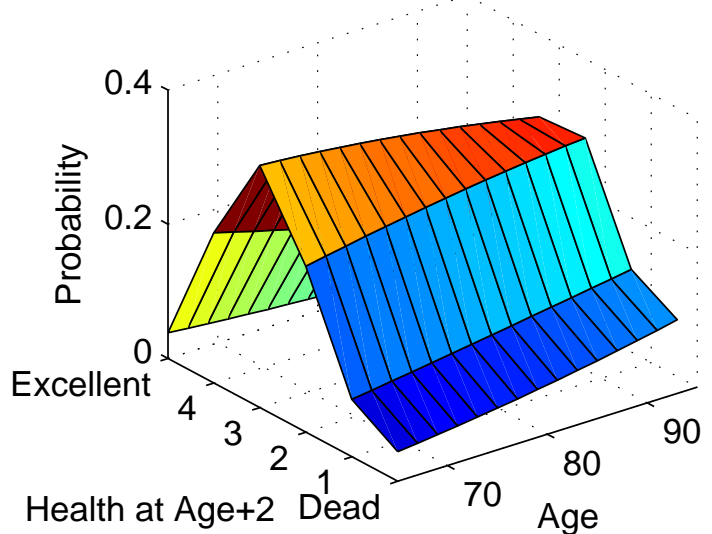

Conditional on Health $=5$ (Excellent)

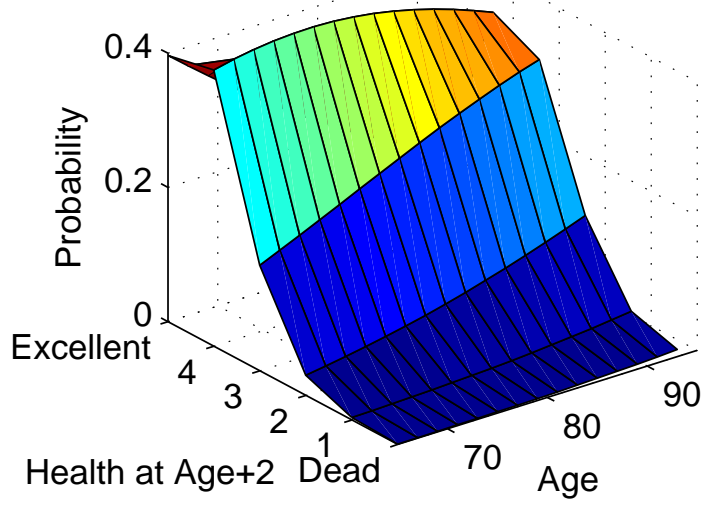

Figure 1: Transition Probabilities for Health Status

The ordered probit model, reported in Table 4, is used to predict the transition probabilities for health status. The predicted probabilities are those for retired unmarried females, born in the 1931-1940 cohort, with medical expenditures below $\$ 500$. 

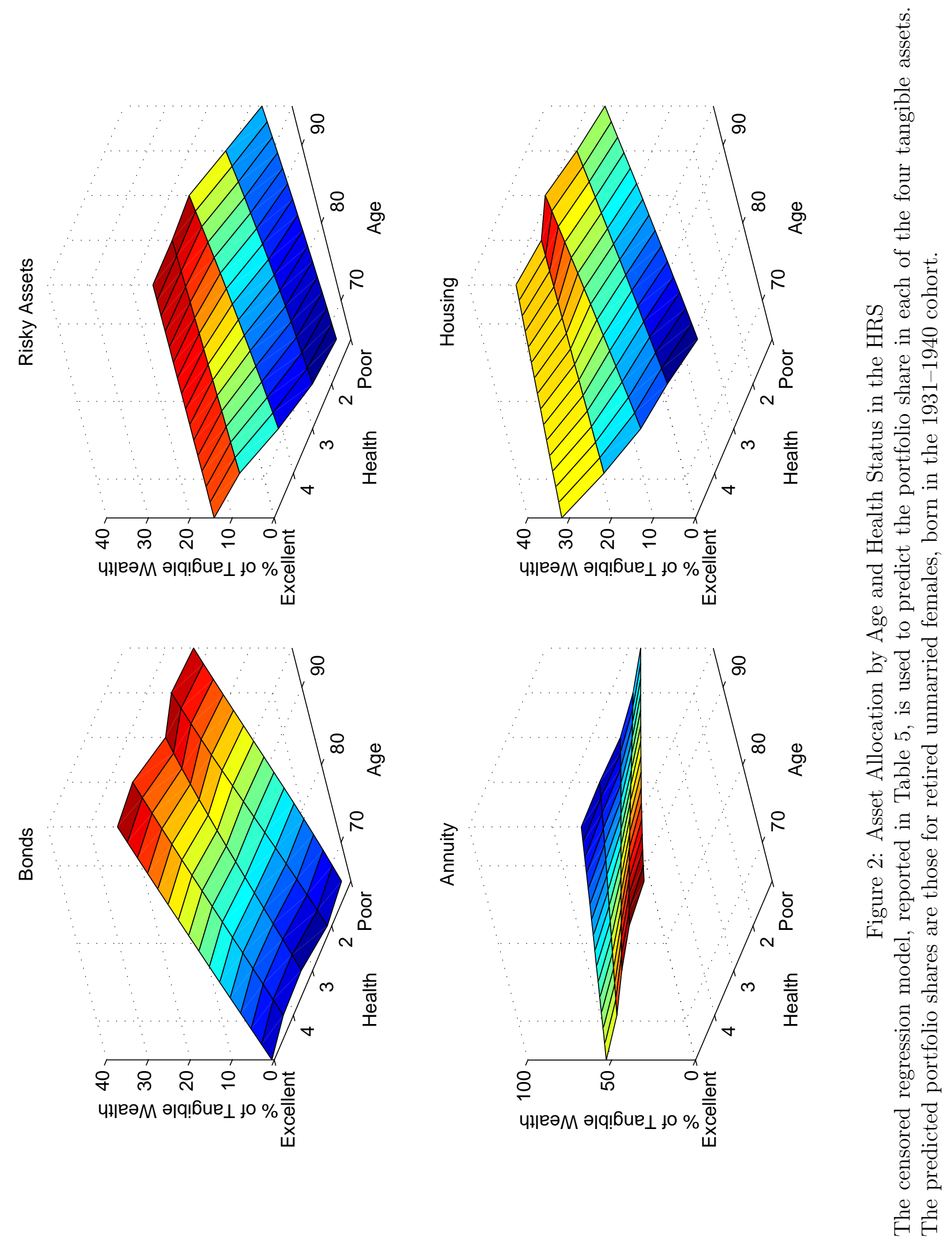
Consumption at Age 65

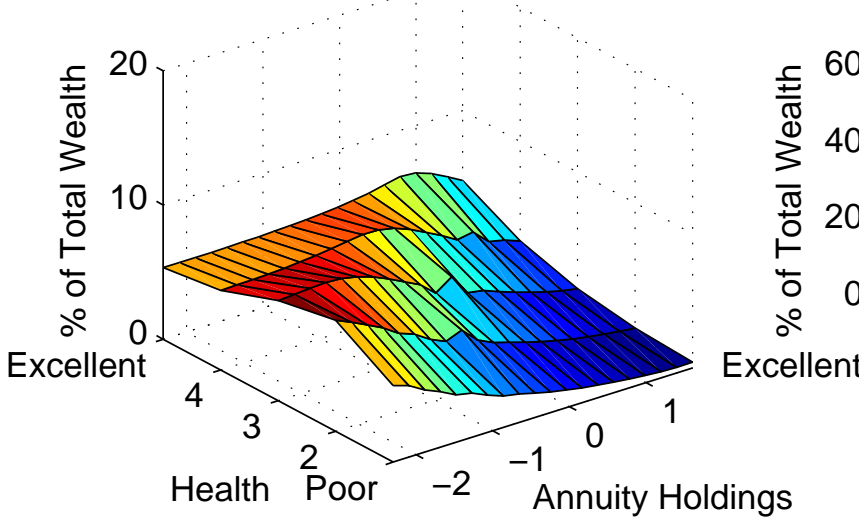

Portfolio Share in Risky Assets at Age 65
Portfolio Share in Bonds at Age 65

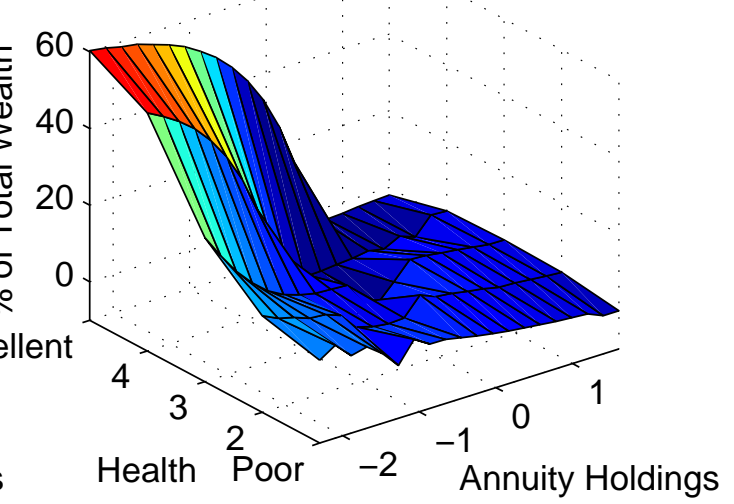

Portfolio Share in Annuity at Age 65
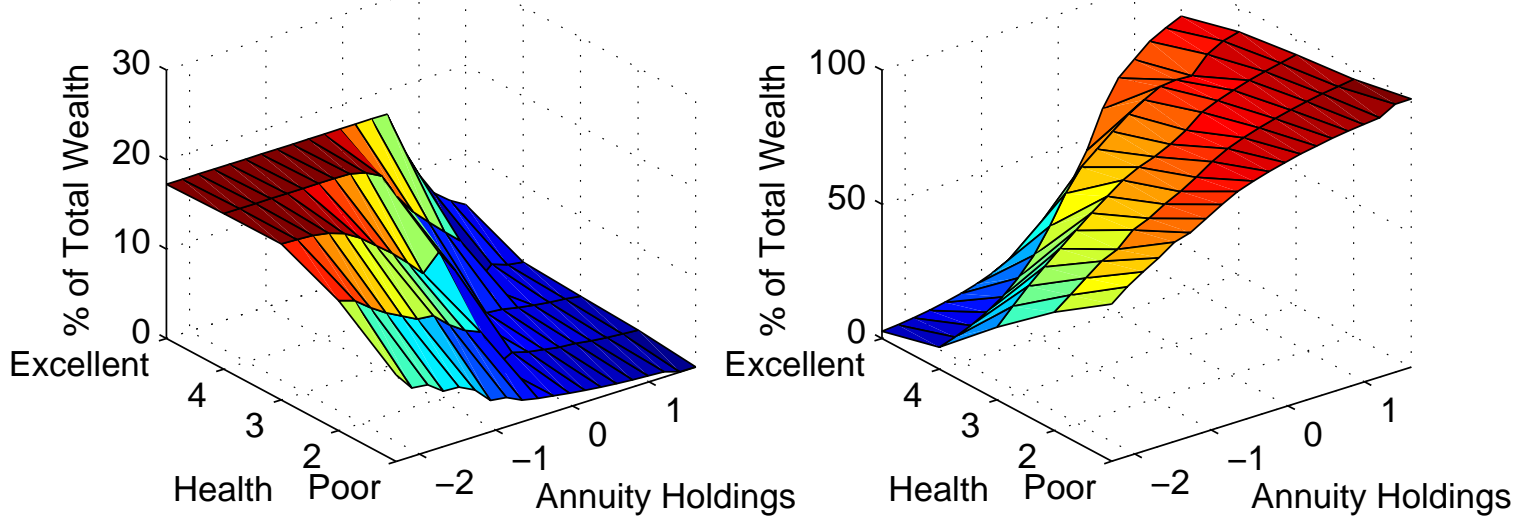

Portfolio Share in Housing at Age 65

Portfolio Share in Health at Age 65
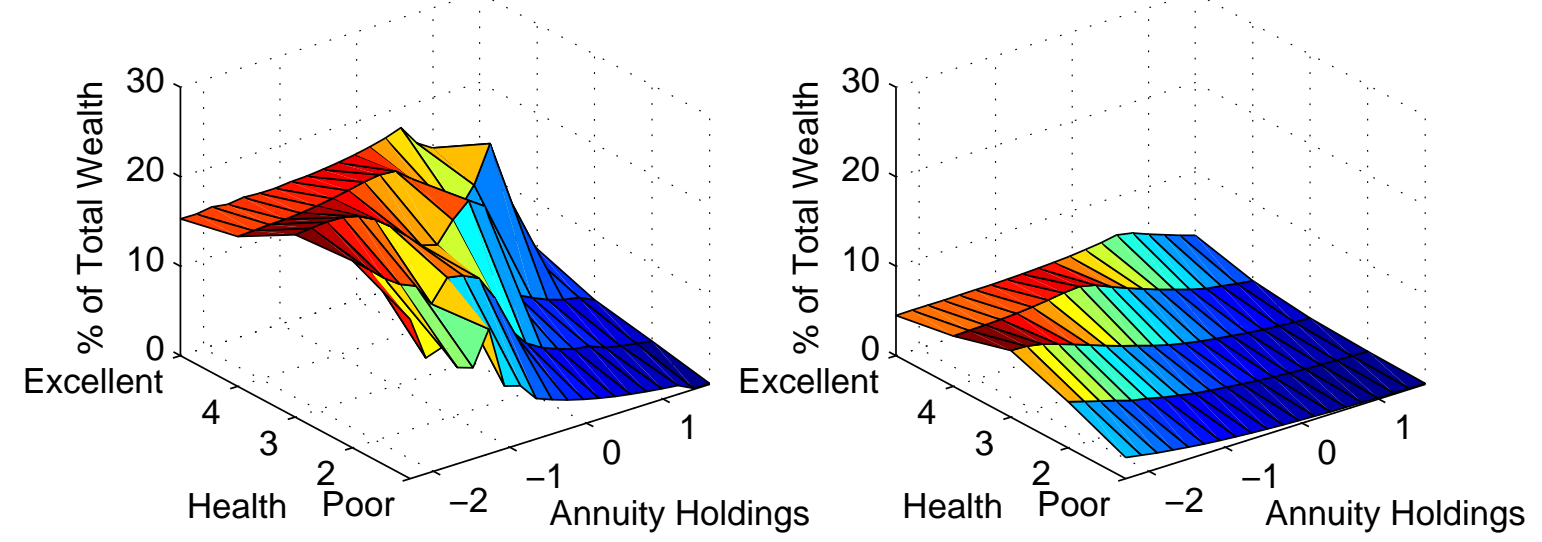

Figure 3: Consumption and Portfolio Policy Functions at Age 65-66

The consumption policy function is shown as a share of total wealth, $c_{t}=C_{t} / \widetilde{W}_{t}$. The portfolio policy functions are shown as a share of total savings, $a_{i t}=A_{i t} /\left(\widetilde{W}_{t}-C_{t}\right)$ for all assets $i=1,2,3, D, H$. All policy functions are shown as a function of health status, $H_{t} \in\left\{H_{P}, H_{F}, H_{G}, H_{V G}, H_{E}\right\}$, and $\log$ of initial annuity holdings, $\log B_{0}$. The relative price of housing is held constant at $P_{1}=1$. 

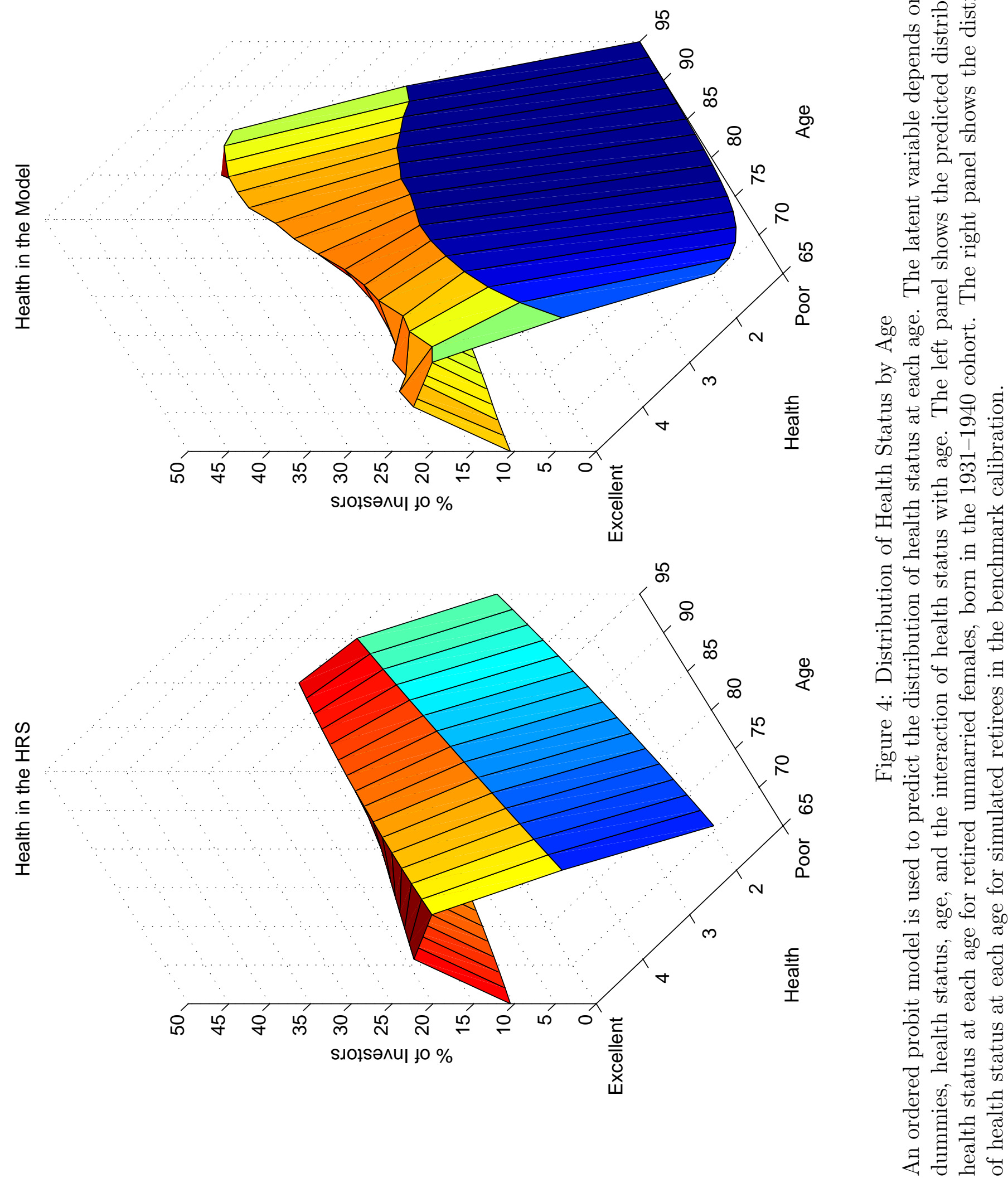

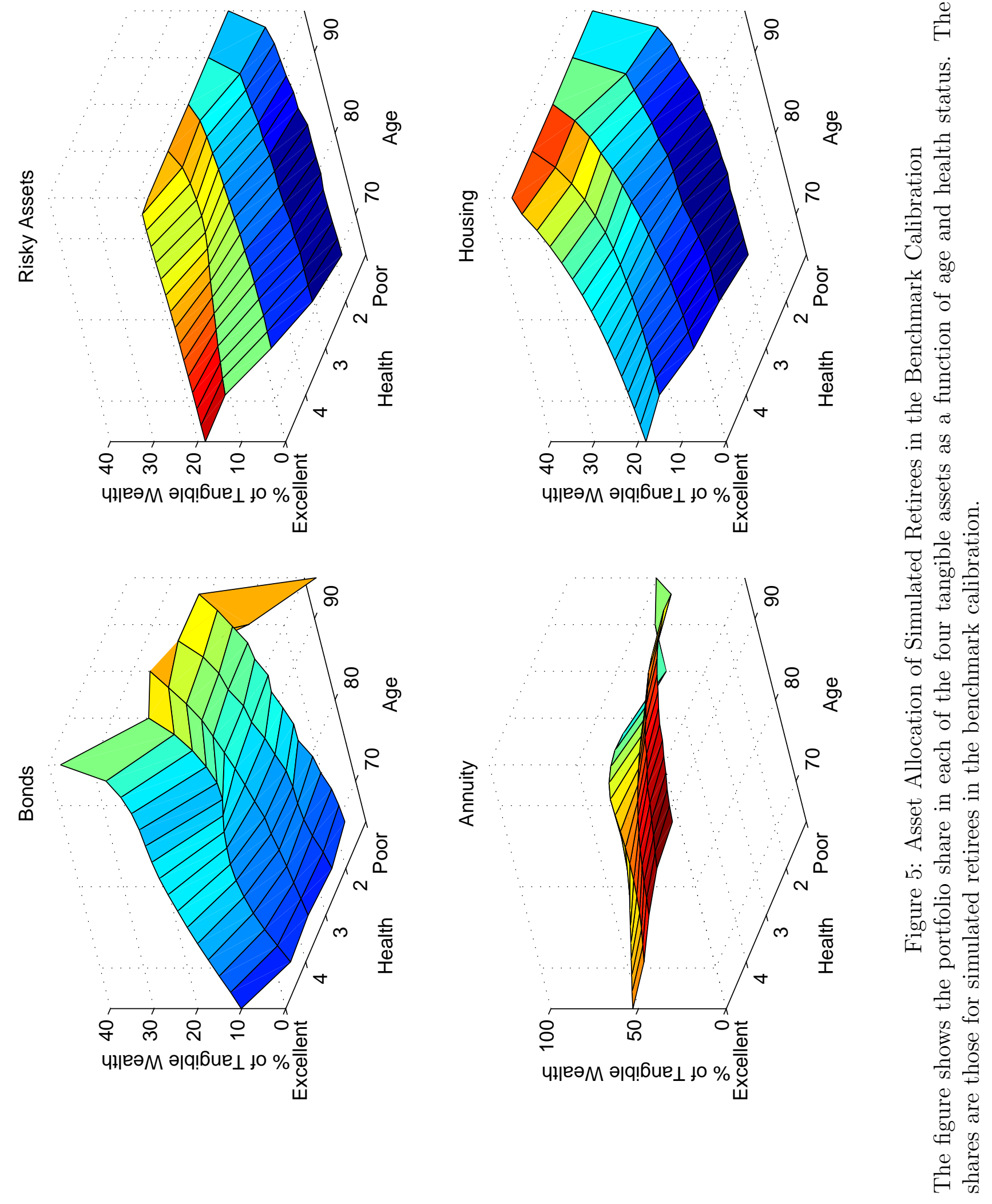

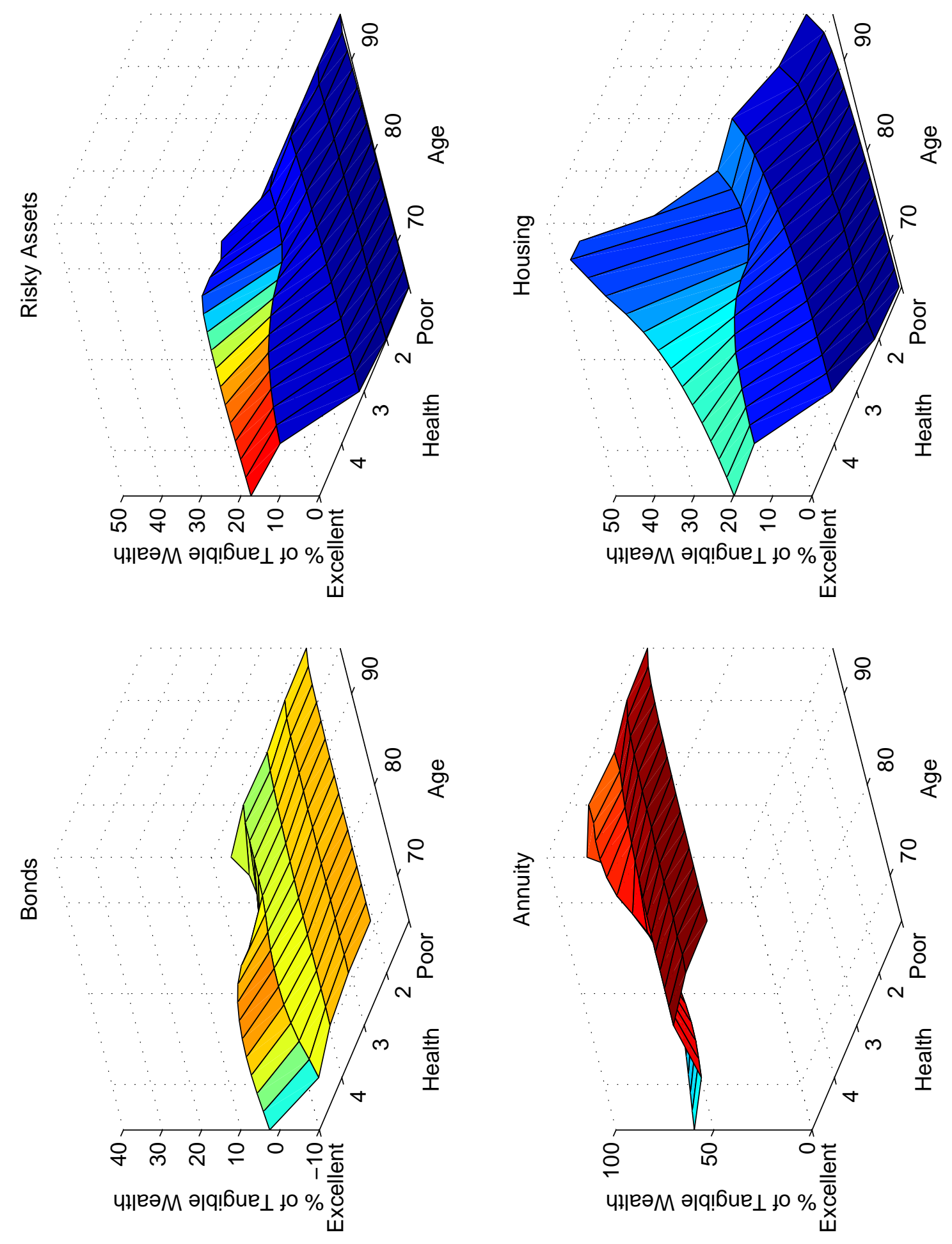

ำ

E

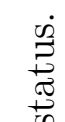

站

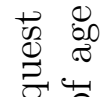

ค

긍ํㅇ

孚寻

एँ

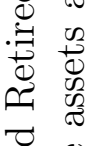

$\underset{0}{0} \frac{0}{0}$

寻

Ч

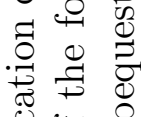

눙

娄

क 01

$\because$ 记

0 궁

పొ

这

유ㅇㅛㅛ

o.

ఫ઼

盗

苛

.

E $\frac{\mathscr{\sigma}}{\sigma}$ 

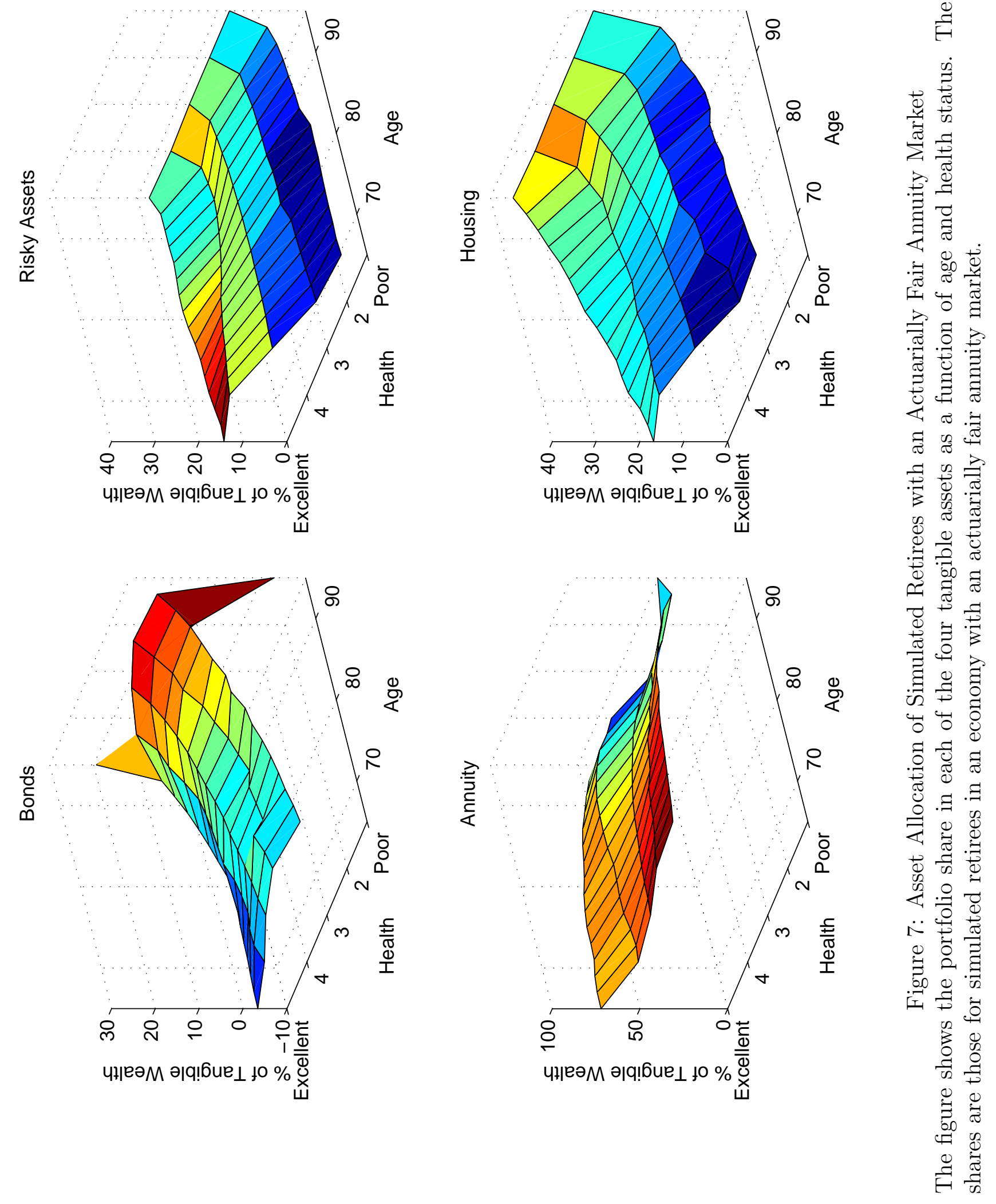


\section{RECENT WORKING PAPERS FROM THE}

\section{CENTER FOR RETIREMENT RESEARCH AT BOSTON COLLEGE}

The Disappearing Defined Benefit Pension and its Potential Impact on the Retirement Incomes of Boomers

Barbara A. Butrica, Howard M. Iams, Karen E. Smith, and Eric J. Toder, January 2009

Retirement and Social Security: A Time Series Approach

Brendan Cushing-Daniels and C. Eugene Steuerle, January 2009

Economic Restructuring and Retirement in Urban China

John Giles, January 2009

Sources of Support for Pension Reform: A Cross-National Perspective

Michelle Dion and Andrew Roberts, January 2009

The Long-Term Effect of the Divorce Revolution: Health, Wealth, and Labor Supply

Kristin Mammen, December 2008

The Response of Household Saving to the Large Shock of German Reunification Nicola Fuchs-Schündeln, November 2008

A Parsimonious Choquet Model of Subjective Life Expectancy

Alexander Ludwig and Alexander Zimper, November 2008

Risky Pensions and Household Saving Over the Life Cycle

David A. Love and Paul A. Smith, November 2008

Identifying Local Differences in Retirement Patterns

Leora Friedberg, Michael Owyang, and Anthony Webb, November 2008

What Effect Do Time Constraints Have on the Age of Retirement?

Leora Friedberg, Wei Sun, Anthony Webb, November 2008

Dual-Eligible Medicaid Spending: Are We on the Flat of the Curve?

Melissa A. Boyle, Joanna N. Lahey, and Margaret E. Czervionke, November 2008

Public Long-Term Care Insurance and the Housing and Living Arrangements of the Elderly: Evidence from Medicare Home Health Benefits

Gary V. Engelhardt and Nadia Greenhalgh-Stanley, November 2008

All working papers are available on the Center for Retirement Research website

(http://www.bc.edu/crr) and can be requested by e-mail (crr@bc.edu) or phone (617-552-1762). 